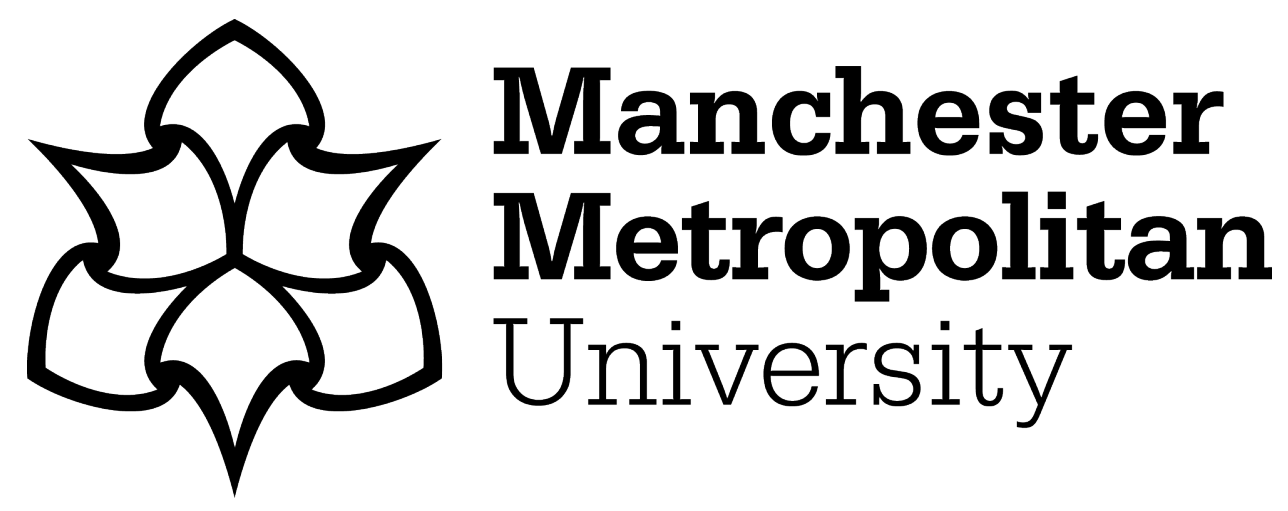

Gotts, NM, van Voorn, GAK, Polhill, JG, de Jong, E, Edmonds, B ORCID logoORCID: https://orcid.org/0000-0002-3903-2507, Hofstede, GJ and Meyer, R (2019) Agent-based Modelling of Socio-Ecological Systems: Models, Projects and Ontologies. Ecological Complexity, 40 (Part B). p. 100728. ISSN 1476-945X

Downloaded from: https://e-space.mmu.ac.uk/621586/

Publisher: Elsevier

DOI: https://doi.org/10.1016/j.ecocom.2018.07.007

Usage rights: Creative Commons: Attribution-Noncommercial-No Derivative Works 4.0

Please cite the published version 


\title{
Agent-Based Modelling of Socio-Ecological Systems: Models, Projects and Ontologies
}

\author{
Nicholas M. Gotts ${ }^{\mathrm{a}}$, George A.K. van Voorn ${ }^{\mathrm{b}}$, J. Gareth Polhill ${ }^{\mathrm{c}}$, Eline de Jong ${ }^{\mathrm{d}}$, \\ Bruce Edmonds ${ }^{\mathrm{e}}$, Gert Jan Hofstede ${ }^{\mathrm{d}}$, Ruth Meyer ${ }^{\mathrm{e}}$ \\ ${ }^{a}$ Corresponding author. Independent researcher, \\ visiting fellow, Centre for Policy Modelling, Manchester Metropolitan University. \\ Postal address: 4 Wolseley Crescent, Edinburgh EH8 7DF, Scotland, UK \\ ${ }^{b}$ Wageningen University and Research, Biometris, \\ Droevendaalsesteeg 1, $6708 \mathrm{~PB}$ \\ P.O. Box 16, 6700 AA, Wageningen, the Netherlands \\ ${ }^{c}$ The James Hutton Institute, Craigiebuckler, \\ Aberdeen AB15 8QH, Scotland, UK \\ ${ }^{d}$ Wageningen University and Research, \\ Hollandseweg 1, 6706 KN, Wageningen, the Netherlands \\ ${ }^{e}$ Centre for Policy Modelling, Manchester Metropolitan University, \\ Oxford Road, Manchester, M15 6BH, UK
}

\begin{abstract}
Socio-Ecological Systems (SESs) are the systems in which our everyday lives are embedded, so understanding them is important. The complex properties of such systems make modelling an indispensable tool for their description and analysis. Human actors play a pivotal role in SESs, but their interactions with each other and their environment are often underrepresented in SES modelling. We argue that more attention should be given to social aspects in models of SESs, but this entails additional kinds of complexity. Modelling choices need to be as transparent as possible, and to be based on analysis of the purposes and limitations of modelling. We recommend thinking in terms of modelling projects rather than single models. Such a project may involve multiple models adopting different modelling methods. We argue that agent-based models (ABMs) are an essential tool in an SES modelling project, but their expressivity, which is their major advantage, also produces problems with model transparency and validation. We propose the use of formal ontologies to make the structure and meaning of models as explicit as possible, facilitating model design, implementation, assessment, comparison and extension.
\end{abstract}

Keywords - Socio-ecological system; Agent-based model; Complexity; Ontology

\section{Introduction}

Socio-Ecological Systems (SESs) consist of interacting biogeophysical components and social actors (individual and collective). They are invariably complex in their dynamics. Most if not all of the systems providing essential ecosystem services to humanity can be classified as SESs; examples include fisheries, agricultural and food systems, and managed forestry systems. The study and governance of SESs have attracted considerable attention, because many are under increasing pressure from anthropogenic sources: growing population, over-utilization, pollution, and climate change (Steffen et al., 2011; Rist et al., 2014). Many concepts currently in use in relation to SESs, including that of resilience, and related notions such as tipping points, 
arise from study of the complex dynamics of these systems. Computational models can help to unravel how these system properties emerge. Modelling guidelines are available for instance in the fields of water management (STOWA/RIZA, 1999; Jakeman et al., 2006; Liu et al., 2008) and environmental policy modelling (Janssen et al., 2005; van der Sluijs et al., 2005; Schmolke et al., 2010; van Voorn et al., 2016), often based on the generic cycle of model development and analysis described by Refsgaard and Henriksen (2004). However, the human side of SES modelling has been given relatively little attention in comparison to the ecological side, and models where social and ecological components are fully integrated are rare. This paper focuses on how to remedy that situation.

Environmental models used for policy assessments generally include social actors and institutions only implicitly, e.g., as parameters to increase or decrease certain system drivers, or as output indicators regarding the fulfillment of certain requirements. For example, many assessments of ecosystem services assume economic rationality, which implies that pricing mechanisms and technological innovations can adequately ensure system resilience. Such assessments often include social drivers and impacts among those they consider, but without modelling the decision-making or social interactions of relevant groups of actors, see for example Vidal-Abarca et al. (2014). This is regrettable from both a scientific and a governance point of view considering that policy usually targets social actors. For example, a farmer may directly affect biogeophysical system components through the use of fertilizer or pesticides, but policy targets the farmer, and not all farmers behave in the same way (see Feola and Binder (2010), and references therein). More generally, not only do different societies organize themselves in different ways (Hofstede et al., 2010), but psychological processes and attributes vary systematically across cultures (Smith et al., 2006). These differences are of the utmost importance to the functioning of SESs. The resilience and sustainability of social and organizational systems, is as important as those of natural systems (Cutter et al., 2010). For instance, social norms have developed among fishers in the Philippines tuna fishery that prevent the simultaneous use of all available fishing sites, creating 'safe patches' for tuna that may thus improve resilience against over-fishing (Libre et al., 2015). If these norms were to collapse, perhaps due to external pressures for "economic rationality", the fishery itself could follow.

Even where the need to use social science approaches is conceded, their role is frequently unduly limited. For example, Daily et al. (2009) say of the assessment of ecosystem services: "[t]he biophysical sciences are central to elucidating the link between actions and ecosystems, and that between ecosystems and services (biophysical models of 'ecological production functions'). The social sciences are central to measuring the value of services to people ('economic and cultural models').". But this does not do justice to the role of social processes in SES. They are more resistant to modelling than biogeophysics, as we discuss. Nevertheless, as indicated by the examples above, and more broadly work such as that of Ostrom (2009), we consider explicit inclusion of social components in SES models essential.

The inclusion of social behaviour raises legitimate concerns in modelling circles about the consequent demands for data, and the objection that with many tuneable parameters, they can produce any desired output. This forces us to think more explicitly about how we model, why we model and the context of modelling in order to choose the most appropriate approach. In this paper, we consider key issues in modelling SESs that arise when including social actors in models, and suggest ways to deal with them. We conclude that agent-based models (ABMs), in which the decision-making of human actors is explicitly represented, are key to SES modelling that does justice to the social aspect of such systems. We concede, however, that agent-based modelling currently suffers significant limitations and drawbacks, particularly with regard to validating, comparing and combining models (Schulze et al., 2017). We therefore propose an approach to ameliorating these disadvantages, based on a shift of focus from models to modelling 
projects, and on the use of formal ontologies (Gruber, 1993).

The paper is structured as follows. In Section 2 we review the properties of SESs, and approaches to assessing them. In Section 3 we look at the roles of data and theory, the significance of modelling aims, and a range of modelling approaches. Section 4 outlines methodological issues concerning agent-based modelling, focusing on the role of ontologies. A summary of our conclusions, and some directions for future work, follow in Section 5.

\section{Why SES modelling is needed, but difficult}

\subsection{The complexity of SES}

SESs are characterized by considerable human influence (it is doubtful if there are now any ecosystems on the planet where such influence can be discounted). SESs display additional kinds (not just degrees) of complexity resulting from social interactions among human individuals or collectives. We first specify what we mean by the complexity of a system.

Systemic complexity has no generally agreed definition, but one useful approach is that of Auyang (1999), according to whom a complex system can be defined as one that "cannot be successfully approximated as a collection of (similar) constituents each responding independently to the situation jointly created by all". A clear counterexample is a molecular gas in equilibrium: each molecule can be regarded as responding to the temperature and pressure of the whole, which in turn are simple outcomes of the spatial and velocity distributions of the collection of molecules. Another example - at least in theory - is a "perfect market": each agent is assumed to act independently, and to respond to price signals which it cannot significantly affect by its own behaviour. Adopting such a definition of systemic complexity puts the emphasis on the system's mereology - the relationships of its parts to each other and to the whole (Gruszczyński and Varzi, 2015), rather than on computational properties of algorithms needed to simulate it or reproduce data streams from it, or other properties of observed quantitative variables. When a reduction to independently responding components is not possible, understanding the system requires the identification of intermediate levels of structure. Focusing on the system's mereological features allows us to identify subclasses of systemic complexity, which illuminate the modelling challenges associated with each kind (see Fig. 1).

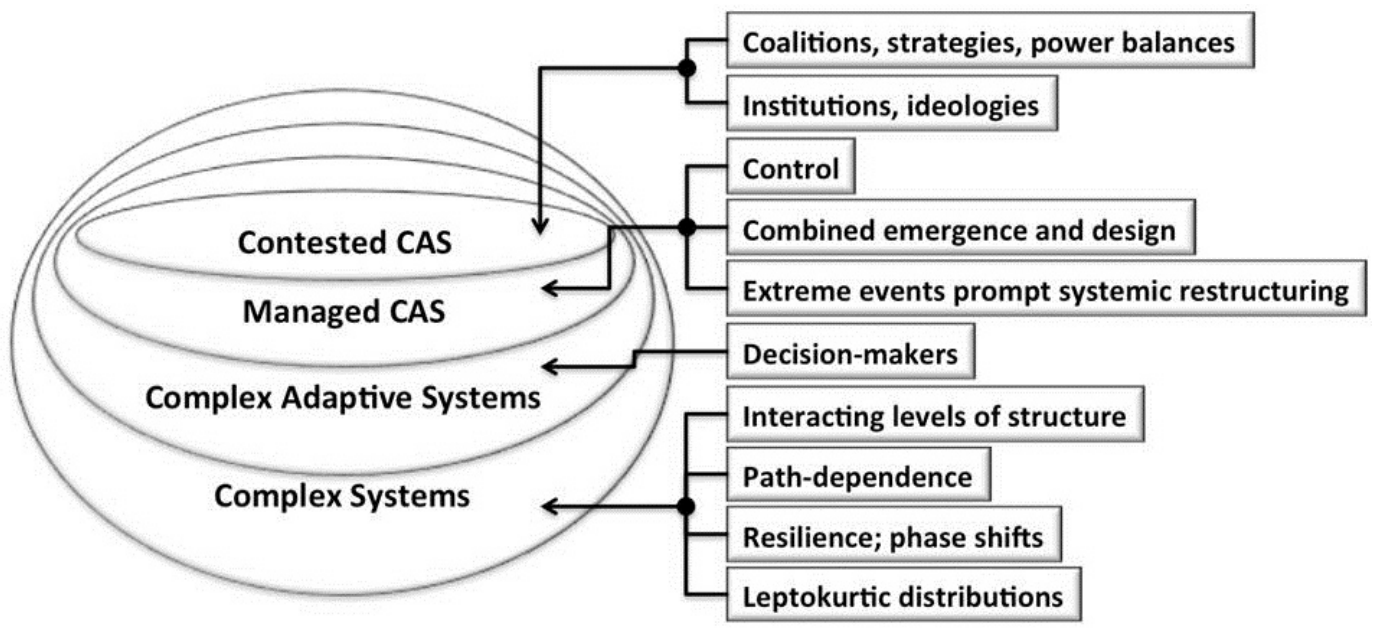

Figure 1: Classes of complex systems. For further explanation see main text. 
All ecosystems can be classified as Complex Systems (the outermost ellipse), i.e., systems in which system components interact to generate emergent behaviour that cannot be adequately understood without the description of intermediate, interacting levels of structure. Complex systems generally display the additional features listed in Fig. 1:

- path-dependence (events at one time can determine or constrain the state of the system for an indefinitely long period);

- resilience and phase shifts: the system has two or more relatively stable states, tending to remain in one such state until internal or external pressures reach a certain tipping point, when it switches rather quickly into another state (Holling, 1973; Bitterman and Bennett, 2016);

- leptokurtic (fat-tailed) distributions of the size of system disturbances: while large disturbances are less common than small ones, their numbers tail off more slowly than an exponential distribution (Zurlini et al., 2006).

All ecosystems are also Complex Adaptive Systems (CAS; the next ellipse, (Holland, 1992)), meaning that they include interacting decision-making components: actors, or agents, the term we use here. Some of an agent's decisions at least can affect its survival, or some other measure of success, such as inclusive fitness, wealth, or happiness. Agents can adapt through evolution or learning. Their decisions may be based on some form of cognitive processing, as with humans, other social animals, human collectives (such as households, firms or governments) or even human artefacts (such as robots or pieces of software); or be simply reactive - perennial plants, for example, may "decide" whether to flower in a given year, depending on the weather and their stored resources.

The difficulty of modelling a CAS has additional dimensions beyond those of complex systems lacking agents, in that adaptive behaviours and interactions between the decisions of multiple agents have to be considered, as does agent diversity. Of course a CAS may be modelled without including these aspects, but the modeller should be aware of them. CASs can be further differentiated according to the range of capabilities displayed by the agents acting within them, as described below.

Managed CASs or MCASs (next ellipse) form a subset of CASs, in which at least one agent is able to assess and attempt to regulate the system at a non-local level. Many SESs are MCASs. In an MCAS, global events and structures may, as in any complex system, emerge from the aggregate of local interactions among components, without any agent intending it - a feature that is frequently stressed in the literature on system complexity; but such events and structures may also be modified, controlled or designed by one or more agents, perhaps using external symbol systems such as written plans, blueprints and charts. Notably, extreme events (such as an ecological catastrophe or stock-market crash) may prompt such agents to undertake restructuring of the system, to recover from (or take advantage of) the extreme event, and prevent (or encourage) a recurrence. The capacity of actors to change a system deliberately to create a new organization is commonly referred to in the literature as "transformability" (Folke et al., 2010; van Apeldoorn et al., 2011). Modelling MCASs adequately requires ways to represent agents themselves capable of representing at least some non-local aspects of the system, and their own actions, and of planning. However, it is possible to model some aspects of such sophisticated agents without attempting to simulate them in full - such a full simulation being an unsolved problem in artificial intelligence.

Finally, contested CASs or CCASs (innermost ellipse) are MCASs that include multiple (influential) agents that can come into conflict because of differing goals. Many SESs fall into this category, including all sufficiently large ones. Here, strategic considerations come into play, and 
the mathematics of non-cooperative game theory, and the areas of artificial intelligence used in the design of game-playing programs become relevant. Work on social dilemmas, cooperation and altruism is also of significance here, and there is already a considerable amount of work on these topics that can be drawn on, including in the agent-based modelling field (Gotts et al., 2003; van Lange et al., 2013). Additional complexity comes from the diverse types of interactions between competing strategic agents. For example, ten Broeke et al. (2018) (this issue) present a suite of models in which different agents cooperate or defect in their interactions, which affects the resilience properties of the system as a whole. It is fair to say that wholly adequate ways to model CCASs are likely to be a long way off, but again, it is possible to model some aspects of strategic interactions.

In addition to being highly complex, all SESs are open, in the sense that factors operating from outside the SES have significant causal influence. This raises a significant issue for validation in models of SESs (Oreskes et al., 1994). It also raises questions of where to draw the system boundary when conceptualizing the empirical world (Hofstede, 1995). Sometimes modelling pragmatics mean that feedback loops involving "slow" variables (Carpenter and Turner, 2001; Crépin, 2007; Walker et al., 2012) are ignored because their effects are negligible over the model's time-frame; we could expect agreement in modelling communities that this is appropriate. However, decisions about whether to include phenomena, and if so, whether to do so as endogenous, or as exogenous driving variables, are also based on more context-specific criteria: the availability of data, or considerations of "elegance" or feasibility and tractability of analysis in the chosen modelling approach. Here, a consensus is less obviously achievable.

There is a further complication to beware of in designing a model of a CCAS: stakeholders will generally attribute perceptions and goals to each other - but these will often be, at least in part, misrepresentations, deliberate or otherwise (Milner-Gulland, 2011). The very fact that stakeholders with opposing views and interests tend to misunderstand and misrepresent each other is a key part of the difficulty of SES modelling. The approach of participatory modelling (discussed in section 3.3) is relevant here.

\subsection{Terminology, indicators and models}

As scientists, we want to understand SES dynamics; as policy-makers or concerned citizens we want to preserve or improve them, and hence need to assess their current state, and how it is changing in relation to those goals. Many contemporary assessments of SESs revolve around the concepts "resilience", "sustainability" and "ecosystem health". These concepts are ill-defined and contested, due both to the fact that different fields of application require different concepts, and to the independent development of these ideas in different disciplines (Janssen et al., 2006; Redman, 2014; Fleurbaey, 2015).

Resilience (in the ecological sense) refers to the capacity of an ecosystem (or socio-ecosystem) to maintain structure, function and feedbacks in the face of disturbance (Folke et al., 2010), but the state maintained may be judged desirable, undesirable or neither. Resilience needs to be evaluated as "resilience of what, to what?" (Carpenter et al., 2001), as not all pressures affect SESs in a similar fashion. The closely related "tipping point" concept emerged from the realization that an ecosystem could have more than one stable state, or "basin of attraction", and that internal or external disturbances could shift it between basins. The disturbance may simply be a gradual change in some variable - such as the amount of a nutrient available. A lake may shift rapidly from an "oligotrophic" (low-nutrient) state, with clear water and oxygen levels high, to a "eutrophic" one, in which algal growth makes it opaque and reduces oxygen levels, as dissolved nutrient levels rise. Nutrient levels may then need to fall considerably below the threshold at which the switch occurred in order to switch it back - the phenomenon of hysteresis 
(Scheffer et al., 2001, 2009, 2012).

Ecosystem health is frequently defined in terms of the absence of toxins; the roster of species present relative to what would be expected; and the ecosystem's ability to recycle waste products. However, for a socio-ecosystem, the welfare of the human inhabitants must also be considered (Costanza, 2012; Lu et al., 2015; O'Brien et al., 2016); and speaking of a system's "health" is in any case best regarded as metaphorical, as ecosystems are not organisms, and what kills some components of an ecosystem may (generally, will) encourage others to flourish.

Finally, the idea of sustainability is linked to human use of the environment, without damaging it in ways that undermine its ability to provide ecosystem services: clean air and water, flood control, recreation, etc. There is, however, extensive argument about what constitutes sustainability, and even whether it is a meaningful term, particularly in combinations such as "sustainable growth", widely regarded as self-contradictory (Bell and Morse, 2008; Bjørn et al., 2015; Sarvajayakesavalu, 2015).

Lack of agreement about how to operationalize the above concepts makes measuring them hard, but more fundamentally, the systemic complexity of CCASs and MCASs makes it inherently difficult to develop simple measures for them. Certain measures may serve as indicators, just as temperature may be an indicator of the health of an individual. Indeed, many indicators have been proposed; a distinction can be made between ecological indicators, i.e., indicators regarding the ecological side of SESs, social indicators, those regarding the social side, and socio-ecological indicators, those relevant to both. However, such indicators will usually not show a one-to-one correlation with emergent SES properties, because they only touch on single facets of the SES much as temperature is an indicator of fever, but not all aspects of human health are correlated with temperature.

Ecological indicators include physical quantities (temperatures, light levels, hydrological measurements, concentrations of chemical species), biophysical measures (biomass, respiration, detritus), species abundance and biodiversity, network measures (food webs, trophic levels, biophysical measures at different trophic levels), maximum disturbance from which recovery is possible, and time to recovery (Siddig et al., 2015; González et al., 2016). Social indicators include individual health and well-being, social capital, and measures of inequality, trust and social cohesion, crime and violence, misuse of alcohol and other drugs, and family structure and functioning (Abbott and Wallace, 2012; Jacob et al., 2013; Klomp and de Haan, 2013; Hicks et al., 2016). Finally, socio-ecological indicators include thermodynamic measures (from "ecological economics"), "footprint" measures, sustainability indicators, and assessments of system resilience, ecosystem services and resource efficiency (Coscieme et al., 2013; Estoque and Murayama, 2014; Li et al., 2014; Lu et al., 2015; Banos-González et al., 2015, 2016; Eisenmenger et al., 2016; Recanatesi et al., 2016).

The very range and variety of indicators makes SES assessment a problematic business. Modelling can guide the choice of indicators for specific assessment purposes. Models represent codified, integrated system knowledge, and can be used to "grow" emergent properties, explore scenarios, and identify distributions of outcomes. However, SES modelling faces at least two major challenges deriving from the intrinsic properties of the systems concerned:

1. It is difficult to untangle the webs of interactions at various spatial, temporal and organizational scales sufficiently to draw a system boundary. There is a trade-off between including too much detail, with the resulting model having too many parameters to feasibly calibrate it or explore its dynamics, or too little detail, oversimplifying. The kinds of dynamics associated with complex systems, discussed above, make data difficult to replicate, with the result that models are left simulating "stylized facts" or "patterns" (Grimm et al., 2005) rather than conforming to data validation criteria associated with traditional statistical measures of model performance. That, and typically limited access to data, mean 
confidence in model predictions is difficult to establish.

2. Many SESs, as noted above, are Contested Complex Adaptive Systems: they include agents capable of thinking about the dynamics of the system as a whole, but differing among themselves over just what those dynamics are, and how, if at all, they should be changed. Typically, at least in cases where a CCAS is contemporary rather than historical, the modeller will be confronted with choices which have political implications: if they adopt the viewpoint favoured by one agent or group of agents, they will quite reasonably be perceived as siding with that agent or agents. Such political implications of modelling choices may occur with respect to historical systems, and indeed to systems other than CCASs, but they are at their most stark for contemporary CCASs. Issues that confront researchers or policy-makers with such clashes between stakeholders (see also section 3.3) are sometimes referred to as "wicked" (Churchman, 1967).

\section{Choosing SES modelling methods}

An SES model, in the broadest sense, is anything that is used to understand a real-world SES through some (real or supposed) resemblance between them. Models can be constructed in different ways, have different requirements for data and relationships to theory, and be used for different purposes. This section discusses these matters.

\subsection{Availability of data and theory}

The ecological aspect of SES modelling is by no means simple, given the sheer number and variety of organisms living just on and below a square meter of grassland or woodland, but as argued above, it is the social aspect that is most in need of development. Yet data collection on human decision-making and social networks, and their effects on SESs, is frequently given far less in the way of attention and resources than collection of data from the biophysical environment.

In addition, there are practical limits to data acquisition. One limitation results from scale mismatches (e.g. feedback responses to human decision-making typically occur on a much slower time-scale and much larger spatial scale than that of the human decision-making itself, as in the case of climate change). Another is the difficulty of extracting reliable data from observations about human behaviour (e.g. people often do not accurately reveal their motivations for doing things, even when they intend to). Again, data on social networks and the interactions taking place within them, and longitudinal data, are often far from adequate.

Hence, in modelling an SES there are often no good data about at least some of the human elements one wishes to include. This does not always invalidate the modelling effort. In the absence of data for a specific element of the model, one can work with estimates, backed up by theory. If an appropriate theory is used, one could for instance show potential emergent behaviours or tipping points that could happen if certain future developments occurred. Determining what data and/or theory to base the model on is therefore an important step in its own right, and one that is linked to the choice of modelling goals and scope. Within psychology and the social sciences, there are abundant theories which are sufficiently articulated to form the basis of a model of a social system, and it is sometimes possible to apply them to SES modelling (Jager et al., 2000; Hofstede, 2017). Conversely, designing and implementing models can assist theory development (Zellner et al., 2014).

However, there are certainly difficulties with this approach. Theories of human behaviour and decision-making are scattered across psychology and the social sciences, most of them focus on isolated aspects of these multifaceted phenomena, they often lack a clear causal basis (Schlüter 
et al., 2017), and frequently leave unstated many details which must be specified for a working simulation (Polhill and Gotts, 2017). Moreover, there is still no generally accepted framework for dealing with key social concepts such as values and norms (Chan et al., 2012), because the social sciences remain methodologically contested disciplines. Thus, the inclusion of human behaviour and decision-making in SES models can require making many assumptions about the relevant actors (Müller-Hansen et al., 2017), even when some support is available from theory.

\subsection{Modelling aims}

There are many different kinds of purpose for a model and these are not always distinguished. We focus here on five principle kinds: prediction, explanation, theoretical exploration, illustration and analogy (or a way of thinking about things). For more about different modelling purposes and their implications, see Edmonds (2017).

The essence of prediction is anticipating aspects of unknown data before they are known. Once a predictive model has been tried on multiple different cases and different conditions successfully one can start to rely upon it. Developing a model for prediction can be quite different from building one for other purposes (Silver, 2012). The gas laws are a simple case of a predictive model - which does not, and need not, explain why it works in order to predict. An example of a predictive social model is Nate Silver's model of the US presidential elections (Silver, 2016). This does not predict a specific result but rather the probability distribution of outcomes, so its accuracy can only be assessed by considering multiple cases (different years, or the results in the various states in a single year, for example). Of course, this approach is not specific to social models.

The second kind of purpose is supporting an explanation - showing how a set of plausible mechanisms might produce outcomes that match some known data (in some well-defined way). If it succeeds, then the workings of the model explain the outcomes (or at least certain aspects of the outcomes). We can test our understanding of the mechanisms with experiments on the model. A typical example of an explanatory model is the Fitzhugh-Nagumo model for spiking neurons (FitzHugh, 1955; Nagumo et al., 1962), which gives no predictions of the membrane potential of neural cells at all but simply illustrates how a spike in this potential develops. Many ABMs and the very similar individual-based models (IBMs) in ecology are aimed at explanation, trying to explain emergent system properties from micro-level processes (Macal and North, 2005; Grimm and Railsback, 2012).

Both prediction and explanation are empirical uses of models: the connection between the model parameters, mechanisms and outcomes should be well-defined and verifiable. However they are very different. The workings of a predictive model do not have to be plausible; it just has to predict successfully. The workings of an explanatory model are the constituents of the explanation that results; if the workings are implausible so is the explanation. It is a mark of mature science when we know how predictive and explanatory models relate so we know why predictions work but often in science one kind of model is developed before the other. For example, the gas laws were discovered before we knew why they worked (random gas molecules bouncing around) while Darwin's explanatory theory of evolution was discovered before any predictions from genetics were possible.

The remaining purposes are not empirical. Theoretical exploration or exposition takes a set of mechanisms and tries to understand the resulting system properties in terms of some theory. If the mathematics is analytically solvable one might obtain a general solution - which may be possible for some models of ordinary or partial differential equations, such as the logistic growth model and the heat equation (Kot, 2001), but in more complicated cases one might just have to calculate or simulate the outcomes, exploring the space of outcomes as thoroughly as is feasible, 
and testing any theoretically-derived hypotheses about the overall behaviour. For example, a "minimal" model of agents harvesting a renewable and diffusing common-pool resource has been used to study the effects of natural selection (ten Broeke et al., 2017) and cooperation (ten Broeke et al., 2018) (this issue) on resilience, using sensitivity analysis to identify contributing factors. Theoretical models do not tell us how observed reality is; to show that a set of theoretical results holds for what is observed, we would then have to establish this as also an explanatory or predictive model. More usually, the theory is not straightforwardly applied, but forms the core of a more extensive model.

Illustrative use of a model just aims to show an idea or particular case. Axelrod's "evolution of cooperation" models (Axelrod, 1984) did not give a general outline of cooperative behaviour in formal games, but did illustrate how cooperation might evolve. The purpose of illustration is to be clear, so illustrative models tend to be simple, but may not meet the rigorous standards of theoretical exposition (and might turn out to capture a vanishingly special case, for example).

A fifth case is to use a model as an analogy - as a way of thinking about things. This is not empirical, because how it relates to what we observe will change with each case it is applied to in a flexible and creative manner. Analogies, whether verbal, visual or encapsulated in a formal model are essential for thinking. We need them to guide the direction of our efforts, they might suggest new hypotheses but they are not reliable pictures of the world.

Illustrative and analogical models are frequently used as a tool for either communication or negotiation (a boundary object). In the case of communication the model is designed to encapsulate a point that someone wants others to understand. Models can be very useful to communicate examples that are too complex to be adequately described using other mechanisms because the recipient can then play with the model gaining rich experience about the interactions, emergence and dynamics. A more complicated use is where a model is used to develop a shared representation or a vehicle for discussing issues in common. In this case the emphasis is not so much on representing an independent phenomenon but rather on its coherence with the stakeholders' perceptions of the issue or situation. See Cash et al. (2003), and for a survey of this kind of use of models Barreteau et al. (2013).

\subsection{The system under-determines the model}

As we have shown, modellers need to consider multiple factors aside from the nature of the real-world systems or class of systems they intend to model (Kelly et al., 2013). These include (but are not limited to):

- What is the purpose of the model?

- What type of data is needed for the development of the model?

- How much data is available for the model?

- What theories are available for use in constructing or constraining the model?

- Who are the model users? Researchers, policy makers, or stakeholders?

All these considerations can influence the best boundaries of the model in regard to content (e.g. which classes, variables and relationships to include and which not), and spatial and temporal scales.

So in general the system under-determines what model, and indeed, what type of model, would be the right outcome of a modelling process. The best answer may be: "No model", at least as far as models in software are concerned, if the requirements stemming from the purpose 
of the model - in terms of data available, theoretical basis, stakeholder involvement and so on cannot be met. The possibility also arises that multiple models, perhaps of different types, may be needed to achieve the modellers' goals. Each model may then serve a different purpose.

We recommend thinking primarily in terms of modelling projects, rather than individual models - see Fulton et al. (2015) and Forrester et al. (2014) for examples of such an approach. A modelling project is an investigation of a specific system (in our case, an SES) or group of systems, in which the design, construction and use of software models is intended to play an important part. It may involve the construction of a number of such models, and in addition, will typically include data collection, theoretical analysis, and in many cases stakeholder involvement. Different models within a project may adopt different modelling methods. They may also adopt different theoretical viewpoints, e.g. there may be a more economically oriented model that assumes all agents behave according to economic rationality, and a socially oriented model that assumes irrational behaviour among agents. Moreover, since in SESs the usual state of affairs is that many stakeholders are involved, and the various stakeholders typically have different views of the system and preferred system states (the system is a CCAS), the modeller may find it useful to produce different simulation models to reflect the viewpoints of different groups of stakeholders.

Those who live their lives in an SES may be the most knowledgeable about it. This makes it desirable to obtain local stakeholder collaboration in model design and refinement. Also, if stakeholders disagree on desirable outputs, or on feasible interventions, a model created without the contribution of certain stakeholders or groups, may be cursorily dismissed by them. So, there are two good reasons for involving stakeholders at model development time: system knowledge, and model acceptance. This has been recognized by SES researchers, and it has given rise to the stream of stakeholder-involving ABM-based research known as companion modelling (Etienne, 2014) or participatory modelling (Voinov et al., 2016). Allison et al. (2018) add a third reason: preventing models being regarded as predictive oracles, contrary to the intentions of the modellers themselves: if stakeholders are involved in designing the models, they may have a better grasp of their limitations, and this message can be reinforced by the modellers.

Nevertheless, these approaches have their own pitfalls. Stakeholders are rarely used to thinking in terms of abstract models, so they require modellers skilled in communication, who build models with understandable interfaces. The modellers must also be able to work effectively in situations involving disagreement, competition for their attention and approval, and conflict. Seidl (2015) argues that there is often insufficient reflection on the processes of participation, and recommends the use of common project protocols or templates, both to facilitate project planning and to improve resulting publications. Stakeholders are, almost by definition, biased: they have a stake in seeing the system in certain ways, ways which justify their own actions. Voinov et al. (2016) note that: "Participatory processes need mechanisms to explicitly recognize human biases and heuristics (i.e. mental shortcuts) when they occur, and to resolve them or compensate for them if needed.", and give a number of recommendations for such mechanisms, including getting a diverse group of participants, and using "structured, accountable, traceable, transparent processes" at all stages of the modelling process. Yet as Barnaud et al. (2005) describe, it is extremely difficult to ensure that those who are at the bottom of social hierarchies (the poor, women, members of ethnic minorities) are able to voice their viewpoints, and the source of unsustainable practices in an SES may lie with national authorities, or others remote from the SES being modelled. Participatory approaches are often valuable, but no panacea. 


\subsection{Approaches to modelling}

At the most general level, we can divide modelling into conceptual, statistical, mathematical and simulation modelling.

- Conceptual modelling examples include fuzzy cognitive maps, conceptual mapping and causal loop diagrams, but they may consist solely of natural language descriptions. A major advantage of graphically encoded conceptual models is that they are a good communication tool; they can be discussed with other researchers and stakeholders without a modelling background. A major disadvantage is that they cannot be unambiguously applied to observed systems, but always involve some amount of interpretation when thus applied.

- Statistical modelling is used for understanding correlation between variables. Examples include Monte Carlo, Bayesian networks, regression models, and structural equation modelling. There are two basic kinds of statistical model: descriptive and generative ( $\mathrm{Ng}$ and Jordan, 2002). A descriptive model abstracts certain properties from a set of data, to give insights into that data or allow different sets of data to be compared. Generative models allow for projections from the data to be made. Usually statistical modelling is used in a descriptive manner for SESs.

- Mathematical modelling is generally associated with theoretically focused models. Most examples are comprised of differential equations, see for example Kuehn et al. (2013). General conclusions can sometimes be analytically derived for these kinds of model, allowing a near complete characterisation of their behaviour. Due to SES complexity, mathematical models tend to be considerably abstracted from any observed target SES.

- Simulation modelling is used when the outcomes of a system cannot be derived analytically, but rather each example scenario needs to be computed individually. They may also be used to improve transparency and comprehensibility in contexts where those with an interest in the model do not understand analytical derivations. Simulation models will typically include adjustable parameters and stochastic elements, and be run many times, producing a range of results. Statistical methods may be applied to this range, and sensitivity testing may be used to determine the effect of changing specific parameters.

Conceptual modelling is always part of the modelling process, but on its own, is insufficient for prediction, explanation, or theoretical exploration of complex systems such as SESs. Statistical modelling approaches are very data-driven and typically assume a static system structure. They are not suitable for understanding emergent properties, which is clearly relevant when SESs are concerned. Mathematical models are explicitly dynamical. However, only models of very limited complexity (in terms of number of state variables, parameters, stochastic and/or spatial components, and types of feedback included) are analytically tractable, and these are mainly suited to serve as caricatures of reality.

Simulation modelling allows for the inclusion of multiple state variables, many parameters, stochastic and/or spatial components, and several feedback mechanisms. Simulations can be based on a system dynamics, cellular automaton or agent-based model approach, or on combinations of these.

Systems dynamics (SD) is commonly used to describe biogeophysical processes, including population, groundwater, and nutrient flow dynamics. SD models are based on a mean field approximation of state variables at an aggregated level. They usually represent a combination of a mathematically explicit description of processes, such as differential equations, and simulation 
using a numerical implementation. A major advantage of SD models is that there are many model analysis methodologies available, including methods that can be used to address concepts such as tipping points and resilience. Major drawbacks are that these models do not allow for lower-level descriptions and handle social processes poorly.

Cellular automata models are frequently used in areas such as land use change prediction and policy (Yang et al., 2014). In these spatially explicit models, each "cell" has a number of possible states, and in a pure cellular automaton model, the state of a cell at time $t+1$ depends only on its own state and those of a limited set of neighbours at time $t$. Such land use change models can be very useful predictive tools, but abstract away the agency of actual land managers, and also impose a fixed spatial structure and set of possible land uses, which take no account of changes in ownership or management, or of land use options. Cellular automata simulations involving commons dilemmas go back to the 1980's, e.g. Axelrod (1984), Nowak and Sigmund (1992), but these focus mainly on the development of optimal or idealised strategies and not on actors' external drivers and internal motivations. In other words, people seldom behave in these idealized ways, which necessitates the inclusion of theory regarding what internally motivates and externally drives people's decisions.

Agent-based modelling is an approach in which decision-makers (agents) of some kind are explicitly represented. Their decisions generally affect both the relative success and interrelationships of the agents themselves, and the environment in which they are placed. The agents may represent individuals, households, firms, states or other collectives, and typically can differ from each other in terms of motivation, abilities or powers, and knowledge. An ABM may well include System Dynamics and/or Cellular Automaton elements representing aspects of the agents' environment (Gaube et al., 2009; Haase et al., 2012; Martin and Schlüter, 2015) or governing the agents' internal processes (Bradhurst et al., 2015; Schieritz and Größler, 2003).

Ideally, there would be a clear set of guidelines providing a universally-agreed specification of the appropriate modelling approach to use based solely on attributes of the empirical world, modelling aims, and the data available. The choice of modelling approach, however, is often more a question of disciplinary norms and individual preferences than of rigorous analysis of criteria. Kelly et al. (2013) do provide a decision tree to guide the choice of modelling approach based on the mix of qualitative and quantitative data available, and availability of existing models for processes and system components; but the tree's decision nodes also require evaluation of modelling purpose, the perceived importance of feedbacks, and the interests of the modeller. Other reviews of modelling approaches are rather less prescriptive. Schlüter et al. (2012) do not make specific recommendations about which approach to use, but instead propose using Ostrom's framework (Ostrom, 2007, 2009) as a basis for justifying modelling choices and making comparisons among various models conceptualising SESs.

A model of a complex system, and in particular of an SES, can range from very simple to highly complicated (where "complicated" means "consisting of many components of different types"). Other things being equal, a simpler model is to be preferred. When a model gets more complicated or complex three major drawbacks start to play an increasing role:

1. The model may become over-fitted, i.e., it starts to fit noise which reduces its applicability for other datasets. If there are more free parameters in the model than can be calibrated using the available data, then an explanatory model may be too easy to fit to the data the 'wiggle room' to fit anything is just too great. Thus the fact that a model fits particular data may not be significant.

2. Limitations in available computational power to run the model can prevent appropriate, adequate exploration of the model.

3. It becomes harder to understand how the model functions. 
Furthermore, more complexity does not necessarily mean that the model is more accurate (Blair and Buytaert, 2016). For the purposes of analogy, a simple model may give more insights than a more complex one; if one aims at illustration, then no more is needed than the minimum of structure and processes to show what is intended. Similarly, for the exposition of theory, one would want to pare down all but the mechanisms of interest.

If a model has a predictive purpose, then it may be possible to feed enough data through it to reveal any patterns, which can then be used to predict new observations. In SESs, however, prediction is rare given the complexity of the systems and the relative paucity of data. Most models of SESs tend to be aimed at least in large part at explanation, to deepen understanding of the system or class of systems modelled in terms of a set of plausible mechanisms.

As mentioned above, a modelling project may need to include multiple simulation models of a single system. One more way in which this may be useful arises out of the problems intrinsic to complex models: constructing different models to represent different levels of granularity or of abstraction. A good explanatory model might be very complex, especially if it integrates both social and ecological aspects. It may then be necessary to construct a model of this model (a metamodel), in order to examine some of the mechanisms involved in a more analytic manner. This theoretical model can then be related to the explanatory model in testable and well-defined ways, gaining some of the benefit of both (Lafuerza et al., 2016).

\section{Agent-Based Modelling of SESs}

\subsection{Advantages of agent-based modelling of SESs}

Modelling aimed at explanation of a system's dynamics in terms of underlying mechanisms requires the model to represent these mechanisms adequately and that means representing them explicitly. Such models necessarily attempt some structural correspondence to a part of the observed and/or conceptualised external world. The question then arises of how much structure and which processes need to be represented in the model. We always have limited resources of time, computation and understanding, so some compromise in terms of a model's faithful representation of the modelled system is almost always necessary (Grimm et al., 2005). However, if a model is too simple, it is likely to omit features of crucial importance. For an SES, these features include the decisions, actions and intentions of human individuals, along with their institutions, knowledge, beliefs, resources and technologies. Schlüter et al. (2012) emphasize coevolutionary processes and micro-level decision-making, while Filatova et al. (2016) stress the kinds of feedback within and between the social and ecological subsystems, links between various organisational scales, and the representation of nonlinear behaviour.

These factors are demonstrably important in real-world SESs. We consider that Agent-Based Models have the potential to capture far more of these key features than any other current approach to SES simulation. They allow for detailed description of heterogeneous individual actors' behaviour, which SD models cannot do, and can generate emergent properties, as the interactions of agents with each other and their environment produce macro-level patterns such as directional or cyclical change, and greater or lesser system resilience. In contrast to typical cellular automata, these macro-level features can in turn be perceived by and influence the agents. Moreover, unlike typical cellular automata agents, ABM agents may be given the power to move, to acquire or lose ownership of or influence on specific parts of that environment, and to establish links with agents other than immediate neighbours.

Another advantage is that ABMs lend themselves well to communicating model structure and behaviour to stakeholders: people in general are used to thinking in terms of the intentions, actions and interactions of both other individuals, and collectives such as households, firms, gov- 
ernments and states. Most people are far less used to thinking in terms of differential equations, or the kinds of dynamics typical of cellular automata.

In sum, it is the expressivity of ABMs that leads us to recommend their use. As we have already noted, ABMs can include systems dynamics and/or cellular automata elements. An SES typically links organisms of very different degrees of behavioural sophistication (such as plants or bacteria on the one hand and farmers or gatherers on the other); and the less sophisticated in particular may be present in very large numbers. Large numbers of comparatively simple agents may be best represented using differential equations or cellular automata, even within a model in which human beings (and possibly some other organisms) are represented as individual agents.

There are different ways to combine SD and ABM models, ranging from loosely coupled or sequential, where the output of one model component is fed to the next, to fully integrated, which incorporates feedbacks between the two (or more) components during a simulation run (Swinerd and McNaught, 2012). Martin and Schlüter (2015) provide an example of the latter (including a detailed procedure for achieving it) with their model of the restoration of a shallow lake being polluted by untreated sewerage from private households. This SES case study links an agent-based model of the social sub-system representing individual house owners and a local authority with a system dynamics model of the ecological sub-system (the lake with two types of fish in a predator-prey relationship). A somewhat similar example (FEARLUS-SPOMM, see Polhill et al. (2013)) is examined in Appendix 1.

\subsection{Drawbacks of agent-based modelling of SESs}

The very expressivity of ABMs, however, is a source of significant drawbacks. Because every agent can have its own individual properties, potentially different from those of all other agents in the model, the number of tunable parameters of an ABM can become enormous, and indeed, difficult to calculate, once we consider that the number of agents and the statistical distributions of their properties and relationships with each other can themselves be model parameters. Given enough parameters, it becomes difficult to establish that there is any set of outputs that could not be produced. However, work is needed to establish the change in realizability of outputs introduced by adding an agent to a model, and how this compares with adding a term to a traditional model (Polhill and Salt, 2017). Of course, by no means all ABMs are intended as empirical models of specific systems, but even for those that are not, the problem of defining the range of acceptable outputs remains.

ABMs can also suffer from a lack of transparency in that it may be difficult to determine (even for the modellers themselves) what specific features of the model represent in the system or type of system being modelled - or indeed, whether they represent anything at all, rather than simply being "scaffolding" necessary for the model to function as a piece of software, and to allow the user to manipulate it. This problem is not unique to ABMs, but that it is a serious issue is indicated by attempts at replication which show that altering seemingly minor aspects of an ABM can radically change the results (Edmonds and Hales, 2003; Janssen, 2007). The lack of this kind of transparency places greater emphasis on code sharing and documentation practice (Edmonds and Polhill, 2015).

In modelling any complex adaptive system, and in particular in modelling SESs, we can be effectively certain that our model will not include all the layers of intermediate structure, or all the kinds of interaction between agents, which are relevant to the behaviour of the real-world system being modelled; any model (not just those that are agent-based) will inevitably be partial in this sense, but this partiality may not be evident to the model's users, and is easily forgotten by its developers.

To keep ourselves as honest as possible as modellers, we propose making as explicit as feasible 
what we have knowingly left out of our models. (The qualifier "knowingly" is a necessary one; given our very limited knowledge of SESs and their "components" (particularly, of people), we can also be pretty certain that we are leaving out more than we are aware of.) "As explicit as feasible" is an elastic term, and deliberately so. We know, as modellers, the pressure to produce a model rapidly, and the space limitations and other constraints of journals and conference papers: emphasising what your model does not cover may not assist you in getting published. But there are now model repositories such as Open $\mathrm{ABM}^{1}$, where model code and documentation can be archived and made available to other researchers. This documentation should, we suggest, include an explicit statement of the model's known limitations, along with its purpose, data requirements, theoretical basis (if any), and stakeholder involvement (if any). The ODD format (Grimm et al., 2006, 2010) is helpful in putting together the necessary documentation for ABMs - similar formats exist for other types of models. In section 4.3, however, we propose a somewhat different although perhaps complementary approach, which we believe will also help in dealing with the other drawbacks of ABMs due to their expressivity: the use of formal ontologies.

\subsection{Ontologies for agent-based models}

An ontology (in the sense relevant here) is a formal account of the entities considered to be involved in some system or type of system, and the relationships between them (Gruber, 1993). For example, considering farming land use, one might distinguish people, households, farms, fields, animals and crops, and specific subtypes of these broad categories. In an ontology each such concept is given an obvious and unique label, which is then used in defining some of the relationships between them. Thus "people run businesses"; "farm businesses own farms"; "a field is part of a farm"; "arable and grazing are types of land use"; and "each field has a land use applied to it". This is illustrated in the (much simplified) ontology depicted in Figure 2.

Ontologies are already in use in many areas of work, including ecosystems research. Up to now, their main use in this area has been for data integration (Poelen et al., 2014; Coetzer et al., 2017), including semi-automated processing of remote sensing data (Myers and Atkinson, 2013), rather than in simulation modelling. Usually an ABM (or any other software model of an ecosystem or SES) is described in natural language, sometimes accompanied by tables and diagrams, and possibly structured according to some protocol such as ODD (Grimm et al., 2006, 2010). The real world system, situation or scenario (or type of system, situation or scenario) the model is intended to represent will also be described in some combination of natural language, tables and diagrams. Particularly for non-specialists, ontologies cannot replace clear and wellstructured natural language descriptions of either models or modelling targets, but we believe they are a promising "mediating formalism" (Gotts and Polhill, 2009) to assist in bridging the gap between program code and natural language description, with major advantages in the process of designing, implementing and assessing a simulation model:

- Formal ontologies can be used to constrain and check complex simulations. Complex simulations have many degrees of freedom and ensuring a simulation is consistent with an ontology helps constrain these degrees. In this way ontologies can be seen as an extension of type-checking in programming languages which is well known to reduce programming errors.

- There are often fundamental differences as to what types of entities and relationships should or can usefully be distinguished in any particular system. Formalizing ontologies

\footnotetext{
${ }^{1}$ http://openabm.org
} 


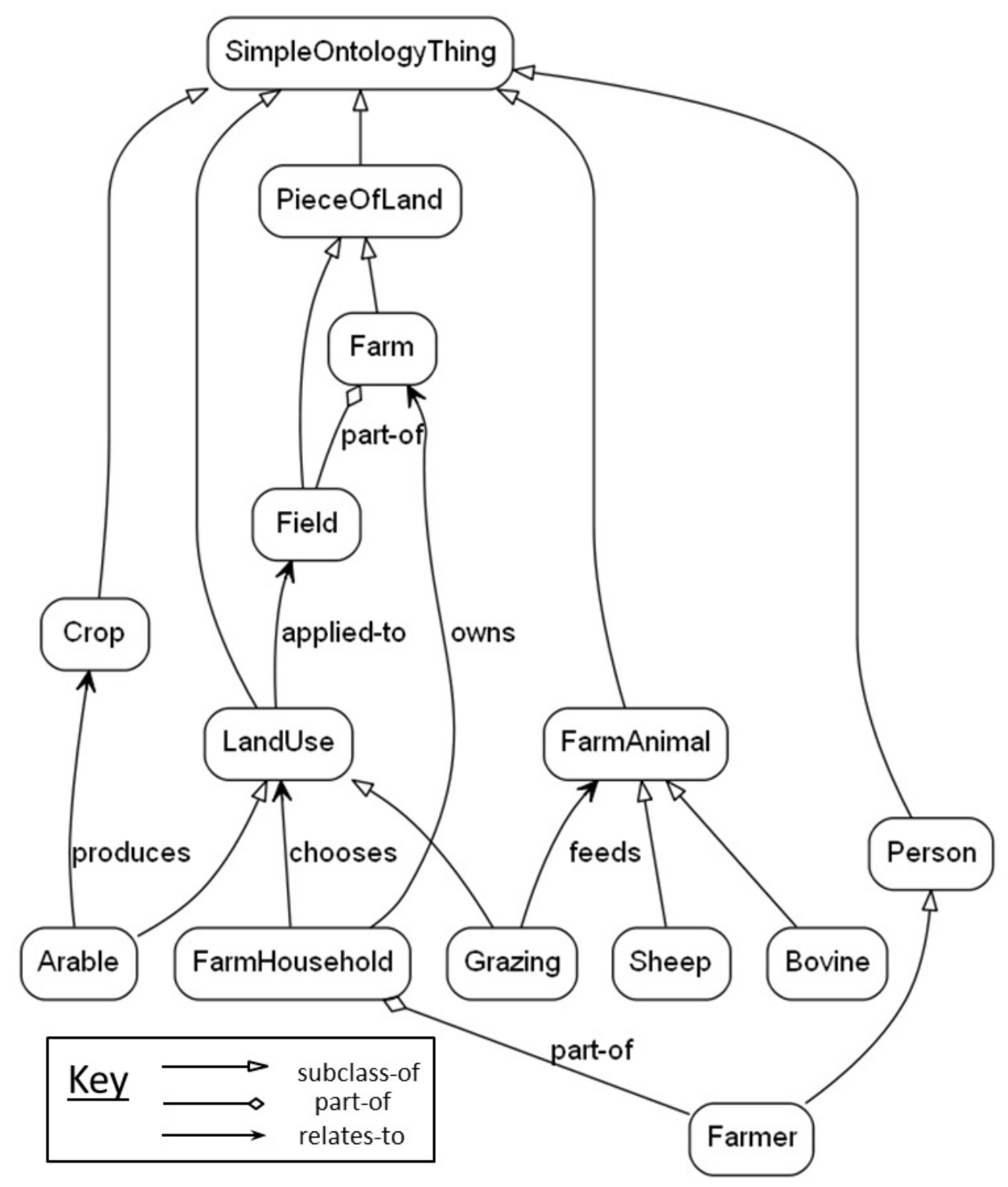

Figure 2: A Simple Ontology.

helps reveal these differences, which are often implicit. This is particularly important where there are experts from several disciplines, or multiple stakeholders, involved in a modelling project.

- Ontologies in diagrammatic form can also be useful in explaining the model to stakeholders and domain experts, although here, care is needed to present no more complexity than will be helpful to the intended audience.

- Polhill and Salt (2017) argue that for any complex model, showing that it can reproduce in its outputs the empirical measurements from the target system does not prove that it captures the underlying processes producing those measurements. They point out that a 
neural network model, in which no attempt is made to capture such underlying processes, can always be tuned to produce an arbitrary set of outputs if it has enough nodes. For any kind of model which does aim to capture the mechanisms responsible for measured system outputs, therefore, its ontological structure (its components and their interactions, whether or not expressed in a formal ontology) must be considered in attempting to validate the model. So if this structure was not specified as part of the model design process, it must be derived from the model itself - Polhill (2015) shows how, for a particular software system often used for ABMs (NetLogo, (Wilensky, 1999)), this process can be partially automated, resulting in a formal ontology. Polhill and Salt (2017) suggest four ways in which such a model-specific ontology can be validated: logical consistency; populating it with instances from the modeled domain (if this proves difficult, it indicates that the ontology is not a good fit); stakeholder and/or expert evaluation (by experts or stakeholders not involved in the original design of the model or its accompanying ontology); and comparison with existing ontologies.

- Ontologies can both be about a view of a system (making them a formalized kind of conceptual model) and be applied to simulation models such as ABMs themselves. But generally, the entities and relationships that exist within such a model are a subset of those pertaining to the modellers' conceptual model of the observed system. Thus when simulating farming land use one might omit the people and conflate these with the farms, thus to focus on what each farm household or business (as a unit) does with the fields on its farm. As noted above, there will also typically be aspects of the simulation model that have no direct counterpart in the system modelled, but are necessary to the model's operation or helpful for the user. The use of ontologies can help to keep the relationships between the simulation model and the system clear, primarily for the modellers themselves. This advantage is discussed in more detail below.

While the most human-accessible representation of ontologies is in diagrams such as Figure 2 they are fully expressed for computational purposes in languages designed for the task, the most common of which is OWL (Cuenca Grau et al., 2008; Horrocks et al., 2003). OWL and similar languages are in turn based on description logics (Baader et al., 2017), formal systems which aim to maximise expressivity while retaining desirable computational properties such as decidability (which guarantees that the process of determining whether or not a statement in the logic follows from a given set of premises will be finite). Software exists for OWL ontology construction and display (Horridge, 2011), for checking that ontologies are well-formed (Tsarkov and Horrocks, 2006; Sirin et al., 2007; Shearer et al., 2008; Bagosi et al., 2014) and for comparison (structural matching) between ontologies (Faria et al., 2013; $\mathrm{Hu}$ and $\mathrm{Qu}, 2008$ ).

The hierarchy of concepts in an ontology will often be a "tangled hierarchy", where a concept may have multiple links to superiors (sheep are ruminants as well as farm animals). An ontology may or may not include specific instances of its classes. If it does, it may also include relationships between these instances: an ontology could specify that Paris is the capital of France, for example. The possible relationships between instances of concepts may themselves also form a tangled hierarchy, which is part of the ontology. Since relationships represented in ontologies may be spatio-temporal, an ontology can encode a spatial layout, or a scenario taking place over time (Gotts and Polhill, 2009).

Ontologies have been used in conjunction with multiple models within a modelling project (not, as it happens, including ABM) in agricultural systems research (Janssen et al., 2011), and in conjunction with integrated assessment models (de Vos et al., 2010). Although de Vos et al. (2010) focus on systems dynamics models, they raise the issues of model validation and transparency noted in section 4.2 as difficulties encountered in using and assessing ABMs. Neither Janssen et al. 
(2011) nor de Vos et al. (2010), however, use ontologies to clarify how the software ABM relates to the system it attempts to capture, as proposed here: their ontologies aim to capture the structure of a software model or set of connected models, while leaving the conceptual model to be described only in natural language. Beck et al. (2010), in contrast, describe a software environment for constructing systems dynamics models from ontologies in the agricultural domain. However, we cannot find subsequent examples of work within this environment.

Here, we propose a somewhat different approach, with the focus on maintaining clarity and transparency in modelling projects that may involve multiple models and multiple modelled systems. In order to specify which aspects of the real world are represented (and which not) in a simulation model, and how, we propose the use of several linked formal ontologies, drawing on ideas from Polhill and Gotts (2006), Polhill and Gotts (2009) and Gotts and Polhill (2009), but adapted to deal with the issues discussed in this paper.

Formal ontologies only encode the structural relationships between the concepts (and maybe individuals) represented - this is all they can do. For example, if an ontology records that farmers grow crops on land they own or rent, neither the ontology, nor any software used to build or manipulate it, knows anything about what a farmer, a crop or land is, or what owning and renting mean, beyond what is explicitly encoded in the terminology used: the same information could be encoded using the labels: $\mathrm{X}, \mathrm{Y}$ and $\mathrm{Z}$ for farmers, crops and land - the use of meaningful terms is simply an aid to interpretation. If we place model entities and relationships, and the real-world entities and relationships they are intended to represent, into distinct but linked ontologies, it may be easier to avoid any confusion between those observed and those in the model. It should also help modellers to keep in mind that the ontologies themselves are just descriptive tools which, inevitably, will leave out or distort many aspects of what they describe.

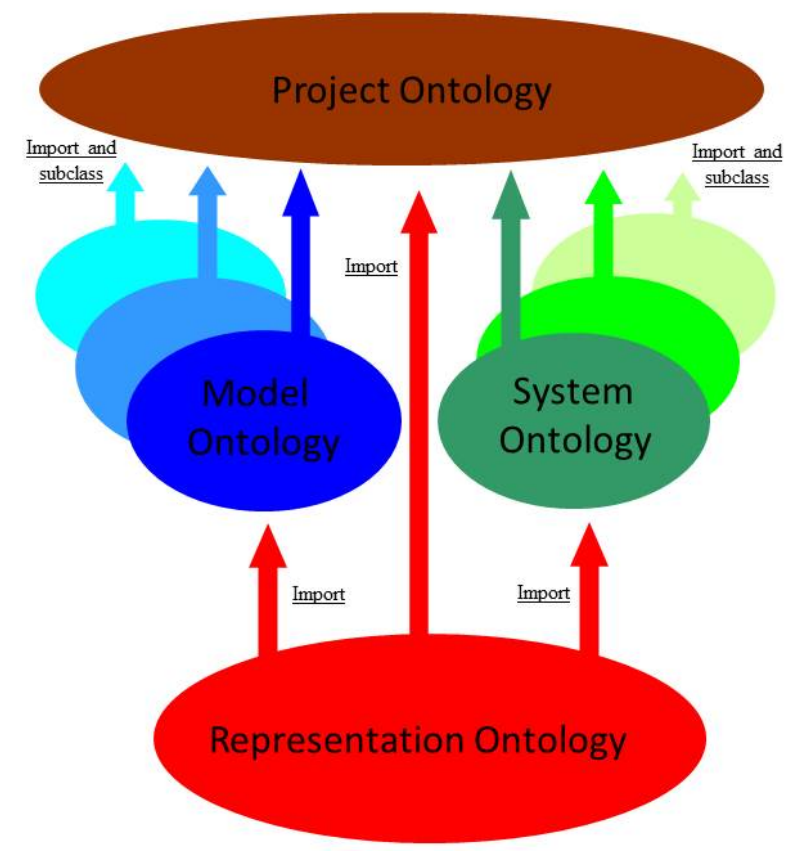

Figure 3: Ontologies for SES Modelling. 
Figure 3 illustrates the set of ontologies that might be used in a modelling project, and the relationships between them. Here there are four kinds of ontology: the project ontology, the system ontology (or ontologies), the model ontology (or ontologies) and the representation ontology.

The most general is the project ontology, which combines the conceptual, primarily qualitative model of a domain of discourse, enquiry or research - such as SESs - with concepts encoding the general approach taken to modelling the domain - such as ABM. It will include the more abstract, high-level terms that are fundamental to conceptualizing the domain, including both terms that apply to real-world items, and those which apply to items within models.

A system ontology would contain concepts, and individuals, intended to capture the entities, relationships and processes present in a specific part of the real world. Primarily, it would encode the modellers' conceptual model; if stakeholders' conceptual models were incompatible with this, the differences would be captured by notations describing these stakeholders' beliefs about the system. The additional ovals represent the fact that a modelling project may cover multiple systems, situations or scenarios. A system ontology imports the project ontology meaning that the terms in the project ontology are available for use in defining terms in the system ontology. The figure illustrates that there may be multiple system ontologies, one for each system modelled within the project; but different system ontologies within a modelling project may encode incompatible conceptual models. However, each must be compatible with the project ontology, and the project ontology may thus require amendment when a new target system is added to the project.

A model ontology is concerned with the entities in a specific model and their relationships. A model ontology, like a system ontology, will import the project ontology. There may be several within a modelling project, and even several corresponding to different models of the same system - for example, models at different levels of detail, or attempting to capture the views of different groups of stakeholders. Again, different model ontologies may not be compatible with each other, so again, the project ontology may need amendment when a new model is added to the project.

The representation ontology encodes the relationships between the system and project ontologies and the model ontology or ontologies. It imports all the other ontologies, and adds only the links between items in the project and system ontologies, and the items that represent them in one or more model ontologies.

A hypothetical example drawn from a real land use change modelling project, FEARLUS (Polhill et al., 2001), and its enhancement to include a species metacommunity model as FEARLUSSPOMM (Polhill et al., 2013) is described in Appendix 1. A much more detailed account of the use of ontologies in a large-scale research project involving ABM (alongside quantitative and qualitative empirical methods) is available in Salt et al. (2016), although this does not employ quite the same approach as proposed here.

\section{Summary and Conclusions}

We have argued that the social aspects of SES need to be modelled explicitly (section 1 and section 2). Given this, however, modelling SESs raises particular problems because:

1. Additional kinds of complexity are involved when a system includes human agents - who may attempt to change the structure and dynamics of the SES they are part of, in conflict, in competition or in cooperation with each other (section 2.1);

2. The terminology used in the assessment of SESs is ill-defined and contested. Important concepts in the assessment of SESs, like "resilience", "sustainability" and "health", are 
highly discipline-dependent, ambiguous, problematic, and contested (section 2.2). These concepts cannot be measured directly, and a wide range of indicators have been used.

3. Closely connected to point 1 , much SES modelling takes place in adversarial political contexts, so that modelling decisions themselves become political (section 2.2).

4. Good data on social aspects of SESs are often unavailable (section 3.1), and although theory can sometimes compensate for absent data, theories of human behaviour are scattered across psychology and the social sciences, generally contested, and often lacking causal mechanisms.

Considering these problems, and the range of possible modelling aims (section 3.2), we conclude that on its own, the nature of the modelled system does not determine the model or models required, and advocate thinking in terms of modelling projects, which may involve one or many simulation models, or even none at all (section 3.3). However, for at least those modelling projects where explanation (deepening the understanding of the system or systems modelled) is an important aim, we consider that among the range of possible approaches to modelling SESs, which we briefly outline (section 3.4), the expressivity of agent-based models (ABMs) is necessary to successful SES modelling, although ABMs may include elements of systems dynamics (SD) and cellular automata $(\mathrm{CA})$ modelling within them (section 4.1).

Along with their advantage in expressivity, and indeed as a consequence of it, ABMs do have significant drawbacks: their numerous tunable parameters pose difficulties for validation and their complex structure for transparency (section 4.2). We suggest a number of ways in which the use of formal ontologies can ameliorate these problems (section4.3) in the context of modelling projects, covering the processes of design, implementation, stakeholder involvement, and validation. We argue in particular that it is vital to make as clear as possible what each model is for, what it includes and what it is known to leave out, and therefore recommend the use of ontologies to encode relationships between the overall project, its models, and the systems modelled.

It should be said that even ABMs have difficulty capturing cross-scale interactions between local, regional, national, continental and global levels. SESs which would once have been relatively self-contained are today increasingly affected, often adversely, by distant events, or by the sum of events over large areas or the entire globe. Changes in the supply of or demand for commodities in one country can lead to the destruction (or at least temporary preservation) of forests in another; species accidentally or deliberately introduced, particularly but not exclusively to isolated regions such as small islands, can devastate local ecosystems; and of course anthropogenic climate change is affecting or will affect every SES on the planet. The need to model such cross-scale networks of causal connections reinforces the need to think in terms of modelling projects, using ABMs on different spatio-temporal and organizational scales, linked through a project ontology.

Similarly, there has been little progress in modelling the kind of social complexity that people inhabit daily and routinely, if by no means always easily. People frequently belong to or take part in multiple social formations, both formal and informal: as members of a household, immediate and extended family, friendship networks, social, professional, political and religious groups. They act as employees or employers, tenants or landlords, buyers and sellers, students and teachers, citizens - to name only a few broad classes of social role. As individuals, we somehow handle these complexities; yet no model, ABM or otherwise, ever deals with more than a small number of the groupings we belong to or the roles we adopt, let alone the complex interactions between them. Progress in developing ABM representations of human agency, and in particular, the way in which the decisions and actions of collectives such as households, firms and states 
emerge out of those of the individuals belonging to them, is therefore essential if agent-based modelling is to fulfill the potential we believe it has.

The over-riding message of this paper is that SES modellers need to make use of agent-based modelling approaches, and to work on extending the capabilities of these approaches to deal with types of complexity beyond their current scope. We recommend the use of formal ontologies as a means to maintain and improve transparency as both individual models and modelling projects grow in complexity. But above all, whether they choose to follow this recommendation or not, they need to make as clear and explicit as they can, to themselves and others - fellow-researchers, policy-makers, stakeholders, and concerned citizens - the aims, the claims, the context, and the limitations of their models. This is both a scientific and a social obligation for all modellers; but the special features of SES modelling (both scientific and political), and the challenges sketched in the preceding paragraphs, make it particularly necessary in that domain.

\section{Acknowledgements}

J. Gareth Polhill receives funding from the Scottish Government's Rural Affairs, Food and the Environment Strategic Research Programme 2016-2021. The work by George A.K. van Voorn and Gert Jan Hofstede was funded by the Wageningen University and Research Resilience investment theme.

\section{References}

Aamodt, A. and Plaza, E. (1994). Case-based reasoning: foundational issues, methodological variations, and system approaches. AI Communications, 7:39-59.

Abbott, P. and Wallace, C. (2012). Social quality: A way to measure the quality of society. Social Indicators Research, 108:153-167.

Allison, A. E. F., Dixon, M. E., Fisher, K. T., and F., T. S. (2018). Dilemmas of modelling and decision-making in environmental research. Environmental Modelling \&5 Software, 99:147-155.

Auyang, S. Y. (1999). Foundations of Complex-System Theories. Cambridge University Press, Cambridge, UK.

Axelrod, R. (1984). The Evolution of Cooperation. Basic Books, New York.

Baader, A., Horrocks, I., Lutz, C., and Sattler, U. (2017). An Introduction to Description Logic. Cambridge University Press, Cambridge, UK.

Bagosi, T., Calvanese, D., Hardi, J., Komla-Ebri, S., Lanti, D., Rezk, M., Rodriguez-Muro, M., Slusnys, M., and Xiao, G. (2014). The Ontop framework for ontology based data access. In Zhao, D., Du, J., Wang, H., Wang, P., Donghong, J., and Pan, J. Z., editors, The Semantic Web and Web Science. 8th Chinese Conference, CSWS 2014, Wuhan, China, August 8-12, 2014, Revised Selected Papers., pages 67-77. Berlin, Germany: Springer-Verlag. The Semantic Web and Web Science. 8th Chinese Conference, CSWS 2014, Wuhan, China, August 8-12, 2014, Revised Selected Papers.

Banos-González, I., Martínez-Fernández, J., and Esteve-Selma, M. Á. (2015). Dynamic integration of sustainability indicators in insular socio-ecological systems. Ecological Modelling, 306:130-144. 
Banos-González, I., Martínez-Fernández, J., and Esteve-Selma, M. Á. (2016). Tools for sustainability assessment in island socio-ecological systems: an application to the Canary Islands. Island Studies Journal, 11(1):9-34.

Barnaud, C., Promburom, P., Bousquet, F., and Trebuil, G. (2005). Companion modelling to facilitate collective land management by Akha villagers in upper northern Thailand. https://www.academia.edu/20497865, accessed 2018-05-31. Communication presented at the Conference on Sustainable Use of Natural Resources and Poverty Dialogue in Montane Mainland South East Asia (MMSEA IV), 16-19 May 2005, Sapa, Vietnam.

Barreteau, O., Bots, P., Daniell, K., Etienne, M., Perez, P., Barnaud, C., Bazile, D., Becu, N., Castella, J.-C., Daré, W., and Trebuil, G. (2013). Participatory approaches. In Edmonds, B. and Meyer, R., editors, Simulating Social Complexity, pages 197-234. Springer. Berlin, Heidelberg.

Beck, H., Morgan, K., Jung, Y., Grunwald, S., Kwon, H., and Wu, J. (2010). Ontology-based simulation in agricultural systems modeling. Agricultural Systems, 103(7):463-477.

Bell, S. and Morse, S. (2008). Sustainability Indicators: Measuring the Immeasurable? Earthscan, New York, second edition.

Bitterman, P. and Bennett, D. (2016). Constructing stability landscapes to identify alternative states in coupled social-ecological agent-based models. Ecology and Society, 21(3):21.

Bjørn, A., Margni, M., Roy, P.-O., Bulle, C., and Hauschild, M. Z. (2015). A proposal to measure absolute environmental sustainability in life cycle assessment. Ecological Indicators, 63:1-13.

Blair, P. and Buytaert, W. (2016). Socio-hydrological modelling: a review asking "why, what and how?". Hydrology and Earth System Sciences, 20:443-478.

Bradhurst, R. A., Roche, S. E., East, I. J., Kwan, P., and Garner, M. G. (2015). A hybrid modeling approach to simulating foot-and-mouth disease outbreaks in Australian livestock. Frontiers in Environmental Science, 3:17. http://journal.frontiersin.org/article/10. 3389/fenvs. 2015.00017, accessed 2018-05-31.

Carpenter, S., Walker, B., Anderies, J. M., and Abel, N. (2001). From metaphor to measurement: resilience of what to what? Ecosystems, 4(8):765-781.

Carpenter, S. R. and Turner, M. G. (2001). Hares and tortoises: interactions of fast and slow variables in ecosystems. Ecosystems, 3:495-497.

Cash, D. W., Clark, W. C., Alcock, F., Dickson, N. M. Eckley, N., Guston, D. H., Jäger, J., and Mitchell, R. B. (2003). Knowledge systems for sustainable development. Proceedings of the National Academy of Sciences, 100:8086-8091.

Chan, K. M. A., Guerry, A. D., Balvanera, P., Klain, S., Satterfield, T., Basurto, X., Bostrom, A., Chuenpagdee, R., Gould, R., Halpern, B. S., Hannahs, N., Levine, J., Norton, B., Ruckelshaus, M., Russell, R., Tam, J., and Woodside, U. (2012). Where are cultural and social in ecosystem services? A framework for constructive engagement. BioScience, 62:744-756.

Churchman, C. W. (1967). Wicked problems. Management Science, 14:141-142.

Cioffi-Revilla, C. and Gotts, N. M. (2003). Comparative analysis of agent-based social simulations: GeoSim and FEARLUS models. Journal of Artificial Societies and Social Simulation, 6(4):10. http://jasss.soc.surrey.ac.uk/6/4/10.html, accessed 2018-05-31. 
Coetzer, W., Moodley, D., and Gerber, A. (2017). A knowledge-based system for generating interaction networks from ecological data. Data $\&$ Knowledge Engineering, 112:55-78.

Coscieme, L., Pulselli, F. M., Jørgensen, S. E., Bastianoni, S., and Marchettini, N. (2013). Thermodynamics-based categorization of ecosystems in a socio-ecological context. Ecological Modelling, 258:1-8.

Costanza, R. (2012). Ecosystem health and ecological engineering. Ecological Engineering, 45:2429.

Crépin, A.-S. (2007). Using fast and slow processes to manage resources with thresholds. Environmental and Resource Economics, 36:191-213.

Cuenca Grau, B., Horrocks, I., Motik, B., Parsia, B., Patel-Schneider, P., and Sattler, U. (2008). OWL 2: The next step for OWL. Journal of Web Semantics, 6:309-322.

Cutter, S. L., Burton, C. G., and Emrich, C. T. (2010). Disaster resilience indicators for benchmarking baseline conditions. Journal of Homeland Security and Emergency Management, $7(1): 51$.

Daily, G. C., Polasky, S., Goldstein, J., Kareiva, P. M., Mooney, H. A., Pejchar, L., Ricketts, T. H., Salzman, J., and Shallenberger, R. (2009). Ecosystem services in decision making: time to deliver. Frontiers in Ecology and the Environment, 7:21-28.

de Vos, M., Koenderink, N., van Ruijven, B., and Top, J. (2010). The use of ontologies in peer reviews of integrated assessment models. International Environmental Modelling \& Software Society (iEMSs) 2010 International Congress on Environmental Modelling \& Software Modelling for Environment's Sake, Fifth Biennial Meeting, Ottawa, Canada, http://www . iemss . org/iemss2010/index . php?n=Main. Proceedings, accessed 2018-05-23.

Edmonds, B. (2017). Different modelling purposes. In Edmonds, B. and Meyer, R., editors, Simulating Social Complexity - A Handbook, chapter 1.4. Springer, Heidelberg, second edition.

Edmonds, B. and Hales, D. (2003). Replication, replication and replication: some hard lessons from model alignment. Journal of Artificial Societies and Social Simulation, 6(4):11. http: //jasss.soc.surrey.ac.uk/6/4/11, accessed 2018-05-31.

Edmonds, B. and Polhill, G. (2015). Open modelling for simulators. In Terán, O. and Aguilar, J., editors, Societal Benefits of Freely Accessible Technologies and Knowledge Resources, pages $237-254$.

Eisenmenger, N., Giljum, S., Lutter, S., Marques, A., Theurl, M. C., Pereira, H. M., and Tukker, A. (2016). Towards a conceptual framework for social-ecological systems integrating biodiversity and ecosystem services with resource efficiency indicators. Sustainability, 8:201.

Estoque, R. C. and Murayama, Y. (2014). Social-ecological status index: A preliminary study of its structural composition and application. Ecological Indicators, 43:183-194.

Etienne, M., editor (2014). Companion Modelling: A Participatory Approach to Support Sustainable Development. Springer.

Faria, D., Pesquita, C., Santos, E., Palmonari, M., Cruz, I. F., and Couto, F. M. (2013). The AgreementMakerLight ontology matching system. In Meersman, R., Panetto, H., Dillon, T., Eder, J., Bellahsene, Z., Ritter, N., De Leenheer, P., and Dou, D., editors, On the Move 
to Meaningful Internet Systems: OTM 2013 Conferences., pages 527-541. Confederated International Conferences CoopIS, DOA-Trusted Cloud, and ODBASE 2013, Graz, Austria, September 9-13, 2013. Proceedings. Lecture Notes in Computer Science 8185.

Feola, G. and Binder, C. R. (2010). Towards an improved understanding of farmers' behaviour: The integrative agent-centred (IAC) framework. Ecological Economics, 69:2323-2333.

Filatova, T., Polhill, J. G., and van Ewijk, S. (2016). Regime shifts in coupled socioenvironmental systems: Review of modelling challenges and approaches. Environmental Modelling 83 Software, 75:333-347.

FitzHugh, R. (1955). Mathematical models of threshold phenomena in the nerve membrane. The Bulletin of Mathematical Biophysics, 17:257-278.

Fleurbaey, M. (2015). On sustainability and social welfare. Journal of Environmental Economics and Management, 71:34-53.

Folke, C., Carpenter, S. R., Walker, B., Scheffer, M., Chapin, T., and Rockstrom, J. (2010). Resilience thinking: integrating resilience, adaptability and transformability. Ecology and Society, 15(4):20.

Forrester, J., Greaves, R., Noble, H., and Taylor, R. (2014). Modeling social-ecological problems in coastal ecosystems: A case study. Complexity, 19(6):73-82.

Fulton, E. A., Boschetti, F., Sporcic, M., Jones, T., Little, L. R., Dambacher, J. M., Gray, R., Scott, R., and Gorton, R. (2015). A multi-model approach to engaging stakeholder and modellers in complex environmental problems. Environmental Science \&3 Policy, 48:44-56.

Gaube, V., Kaiser, C., Wildenberg, M., Adensam, H., Fleissner, P., Kobler, J., Lutz, J., Schaumberger, A., Schaumberger, J., Smetschka, B., Wolf, A., Richter, A., and Haberl, H. (2009). Combining agent-based and stock-flow modelling approaches in a participative analysis of the integrated land system in Reichraming, Austria. Landscape Ecology, 24(9):1149-1165.

González, J., Ortiz, M., Rodríguez-Zaragoza, F., and Ulanowicz, R. E. (2016). Assessment of long-term changes of ecosystem indexes in Tongoy Bay (SE Pacific coast): Based on trophic network analysis. Ecological Indicators, 69:390-399.

Gotts, N. M. and Polhill, J. G. (2009). Narrative scenarios, mediating formalisms, and the agent-based simulation of land use change. In Squazzoni, F., editor, Epistemological Aspects of Computer Simulation in the Social Sciences. Second International Workshop EPOS 2006, Brescia, Italy, October 5-6, 2006. Revised Selected and Invited Papers, Lecture Notes in Artificial Intelligence 5466, pages 99-116. Springer, Berlin, Heidelberg.

Gotts, N. M., Polhill, J. G., and Law, A. N. R. (2003). Agent-based simulation in the study of social dilemmas. Artificial Intelligence Review, 19(1):3-92.

Grimm, V., Berger, U., Bastiansen, F., Eliassen, S., Ginot, V., Giske, J., Goss-Custard, J., Grand, T., Heinz, S. K., Huse, G., Huth, A., Jepsen, J. U., Jørgensen, C., Mooij, W. M., Müller, B., Pe'er, G., Piou, C., Railsback, S. F., Robbins, A. M., Robbins, M. M., Rossmanith, E., Rüger, N., Strand, E., Souissi, S., Stillman, R. A., Vabø, R., Visser, U., and DeAngelis, D. L. (2006). A standard protocol for describing individual-based and agent-based models. Ecological Modelling, 198(1):115-126. 
Grimm, V., Berger, U., DeAngelis, D. L., Polhill, J. G., Giske, J., and Railsback, S. F. (2010). The ODD protocol: a review and first update. Ecological Modelling, 221(23):2760-2768.

Grimm, V. and Railsback, S. F. (2012). Designing, formulating, and communicating agent-based models. In Heppenstall, A., Crooks, A., See, L., and Batty, M., editors, Agent-Based Models of Geographical Systems, pages 361-377. Springer, Dordrecht.

Grimm, V., Revilla, E., Berger, U., Jeltsch, F., Mooij, W., Railsback, S., Thulke, H.-H., Weiner, J., Wiegand, T., and DeAngelis, D. L. (2005). Pattern-oriented modeling of agent-based complex systems: Lessons from ecology. Science, 310:987-991.

Gruber, T. R. (1993). A translation approach to portable ontology specification. Knowledge Acquisition, 5:199-220.

Gruszczyński, R. and Varzi, A. C. (2015). Mereology then and now. Logic and Logical Philosophy, 24:409-427.

Haase, D., Haase, A., Kabisch, N., Kabisch, S., and Rink, D. (2012). Actors and factors in land-use simulation: The challenge of urban shrinkage. Environmental Modelling \& Software, 35:92-103.

Hicks, C. C., Levine, A., Agrawal, A., Basurto, X., Breslow, S. J., Carother, C., Charnley, S., Coulthard, S., Dolsak, N., Donatuto, J., Garcia-Quijano, C., Mascia, M. B., Norman, K., Poe, M. R., Satterfield, T., St. Martin, K., and Levin, P. S. (2016). Engage key social concepts for sustainability. Science, 352(6281):38-40.

Hofstede, G., Hofstede, G. J., and Minkov, M. (2010). Cultures and Organizations, Software of the Mind. McGraw Hill, New York, third edition.

Hofstede, G. J. (1995). Open problems, formal problems. Journal of Decision Systems, 4:155-165.

Hofstede, G. J. (2017). GRASP agents: social first, intelligent later. AI and Society. https: //doi.org/10.1007/s00146-017-0783-7, accessed 2018-05-31.

Holland, J. H. (1992). Complex adaptive systems. Daedalus, 121:17-30.

Holling, C. S. (1973). Resilience and stability of ecological systems. Annual Review of Ecology and Systematics, 4:1-23.

Horridge, M. (2011). A Practical Guide To Building OWL Ontologies Using Protégé 4 and CO-ODE Tools Edition 1.3. http://mowl-power.cs.man.ac.uk/protegeowltutorial/ resources, accessed 2018-05-31.

Horrocks, I., Patel-Schneider, P. F., and van Harmelen, F. (2003). From SHIQ and RDF to OWL: The making of a web ontology language. Journal of Web Semantics, 1:7-26.

$\mathrm{Hu}, \mathrm{W}$. and Qu, Y. (2008). Falcon-AO: A practical ontology matching system. Web Semantics: Science, Services and Agents on the World Wide Web, 6(3):237-239.

Jacob, S., Weeks, P., Blount, B., and Jepson, M. (2013). Development and evaluation of social indicators of vulnerability and resiliency for fishing communities in the Gulf of Mexico. Marine Policy, 37:86-95.

Jager, W., Janssen, M. A., De Vries, H. J. M., De Greef, J., and Vlek, C. A. J. (2000). Behaviour in commons dilemmas: Homo economicus and Homo psychologicus in an ecological-economic model. Ecological Economics, 35:357-379. 
Jakeman, A. J., Letcher, R. A., and Norton, J. P. (2006). Ten iterative steps in development and evaluation of environmental models. Environmental Modelling \& Software, 21:602-614.

Janssen, A., Athanasiadis, I. N., Bezlepkina, I., Knapen, R., Li, H., Domínguez, I. P., Rizzoli, A. E., and van Ittersum, M. K. (2011). Linking models for assessing agricultural land use change. Computers and Electronics in Agriculture, 76:148-160.

Janssen, M. A. (2007). Coordination in irrigation systems: An analysis of the Lansing-Kremer model of Bali. Agricultural Systems, 93:170-190.

Janssen, M. A., Schoon, M. L., Kee, W., and Börnere, K. (2006). Scholarly networks on resilience, vulnerability and adaptation within the human dimensions of global environmental change. Global Environmental Change, 16:240-252.

Janssen, P. H. M., Petersen, A. C., van der Sluijs, J. P., Risbey, J., and Ravetz, J. R. (2005). A guidance for assessing and communicating uncertainties. Water Science \& Technology, $52: 125-131$.

Kelly, R. A., Jakeman, A. J., Barreteau, O., Borsuk, M. E., El Sawah, S., Hamilton, S. H., Henriksen, H. J., Kuikka, S., Maier, H. R., Rizzoli, A. E., van Delden, H., and Voinov, A. A. (2013). Selecting among five common modelling approaches for integrated environmental assessment and management. Environmental Modelling \& Software, 47:159-181.

Klomp, J. and de Haan, J. (2013). Political regime and human capital: A cross-country analysis. Social Indicators Research, 111:45-73.

Kot, M. (2001). Elements of Mathematical Ecology. Cambridge University Press, Cambridge, UK.

Kuehn, C., Siegmund, S., and Gross, T. (2013). Dynamical analysis of evolution equations in generalized models. IMA Journal of Applied Mathematics, 78:1051-1077.

Lafuerza, L. F., Dyson, L., Edmonds, B., and McKane, A. J. (2016). Staged models for interdisciplinary research. PLoS ONE, 11(6):e0157261.

Li, Y., Shi, Y., Qureshi, S., Bruns, A., and Xiaodong, Z. (2014). Applying the concept of spatial resilience to socio-ecological systems in the urban wetland interface. Ecological Indicators, $42: 135-146$.

Libre, S. V. D., van Voorn, G. A. K., ten Broeke, G. A., Bailey, M., Berentsen, P., and Bush, S. R. (2015). Effects of social factors on fishing effort: The case of the Philippine tuna purse seine fishery. Fisheries Research, 172:250-260.

Liu, Y., Gupta, H., Springer, E., and Wagener, T. (2008). Linking science with environmental decision making: Experiences from an integrated modeling approach to supporting sustainable water resources management. Environmental Modelling \& Software, 23:846-858.

Lu, Y., Wang, R., Zhang, Y., Su, H., Wang, P., Jenkins, A., Ferrier, R. C., Bailey, M., and Squire, G. (2015). Ecosystem health towards sustainability. Ecosystem Health and Sustainability, $1(1): 2$.

Macal, C. M. and North, M. J. (2005). Tutorial on agent-based modeling and simulation. In Kuhl, M., Steiger, N., Armstrong, F., and Joines, J., editors, Proceedings of the Winter Simulation Conference, 2005, pages 2-15. 
Martin, R. and Schlüter, M. (2015). Combining system dynamics and agent-based modeling to analyze social-ecological interactions - an example from modeling restoration of a shallow lake. Frontiers in Environmental Science, 3:66. http://journal.frontiersin.org/article/10. 3389/fenvs. 2015.00066, accessed 2018-05-31.

Milner-Gulland, E. J. (2011). Integrating fisheries approaches and household utility models for improved resource management. Proceedings of the National Academy of Sciences, 108(4):1741-1746.

Moilanen, A. (2004). SPOMSIM: software for stochastic patch occupancy models of metapopulation dynamics. Ecological Modelling, 179:533-550.

Müller-Hansen, F., Schlüter, M., Mäs, M., Donges, J. F., Kolb, J. J., Thonicke, K., and Heitzig, J. (2017). Towards representing human behavior and decision making in earth system models - an overview of techniques and approaches. Earth System Dynamics, 8:977-1007.

Myers, T. and Atkinson, I. (2013). Eco-informatics modelling via semantic inference. Information Systems, 38:16-32.

Nagumo, J., Arimoto, S., and Yoshizawa, S. (1962). An active pulse transmission line simulating nerve axon. Proceedings of the IRE, 50:2061-2070.

Ng, A. Y. and Jordan, M. I. (2002). On discriminative vs. generative classifiers: A comparison of logistic regression and naive Bayes. In Dietterich, T., Becker, S., and Ghahramani, Z., editors, Advances in Neural Information Processing Systems 14, pages 841-848. MIT Press.

Nowak, M. and Sigmund, K. (1992). Tit for tat in heterogeneous populations. Nature, 355:250252.

O'Brien, A., Townsend, K., Hale, R., Sharley, D., and Pettigrove, V. (2016). How is ecosystem health defined and measured? A critical review of freshwater and estuarine studies. Ecological Indicators, 69:722-729.

Oreskes, N., Shrader-Frechette, K., and Belitz, K. (1994). Verification, validation, and confirmation of numerical models in the earth sciences. Science, 263:641-646.

Ostrom, E. (2007). A diagnostic approach for going beyond panaceas. Proceedings of the National Academy of Sciences, 104:15181-15187.

Ostrom, E. (2009). A general framework for analyzing sustainability of social-ecological systems. Science, 325:419-422.

Poelen, J. H., Simons, J. D., and Mungall, C. J. (2014). Global biotic interactions: An open infrastructure to share and analyze species-interaction datasets. Ecological Informatics, 24:148159 .

Polhill, J. G. (2015). Extracting OWL ontologies from agent-based models: A NetLogo extension. Journal of Artificial Societies and Social Simulation, 18(2):15. http://jasss.soc.surrey. ac.uk/18/2/15.html, accessed 2018-05-31.

Polhill, J. G., Gimona, A., and Gotts, N. M. (2013). Nonlinearities in biodiversity incentive schemes: A study using an integrated agent-based and metacommunity model. Environmental Modelling \& Software, 45:74-91. 
Polhill, J. G. and Gotts, N. M. (2006). A new approach to modelling frameworks. In Proceedings of the First World Congress on Social Simulation (WCSS 2006), Kyoto University, Kyoto, Japan, 21-25 August 2006, volume 1, pages 215-222. https://www.researchgate. net/profile/J_Polhill/publication/228646877, accessed 2018-05-31.

Polhill, J. G. and Gotts, N. M. (2009). Ontologies for transparent integrated human-natural systems modelling. Landscape Ecology, 24:1255-1267.

Polhill, J. G. and Gotts, N. M. (2017). How precise are the specifications of a psychological theory? Comparing implementations of Lindenberg and Steg's goal-framing theory of everyday pro-environmental behaviour. In Jager, W., Verbrugge, R., Flache, A., de Roo, G., Hoogduin, L., and Hemelrijk, C., editors, Advances in Social Simulation 2015, pages 341-354. Springer. Revised and extended version of paper presented at Social Simulation Conference 2015, 11th Conference of the European Social Simulation Association, Groningen, Netherlands, 14th-18th September 2015.

Polhill, J. G., Gotts, N. M., and Izquierdo, L. R. (2008). FEARLUS Model 1-1-5 User Guide. http://macaulay.webarchive.hutton.ac.uk/fearlus/FEARLUS-model1-1-5-UG. pdf, accessed 2018-05-20.

Polhill, J. G., Gotts, N. M., and Law, A. N. R. (2001). Imitative versus non-imitative strategies in a land use simulation. Cybernetics and Systems, 32:285-307.

Polhill, J. G. and Salt, D. (2017). The importance of ontological structure: Why validation by 'fitto-data' is insufficient. In Edmonds, B. and Meyer, R., editors, Simulating Social Complexity: A Handbook, pages 141-172. Springer International Publishing, Cham.

Recanatesi, F., Clemente, M., Grigoriadis, E., Ranalli, F., Zitti, M., and Salvati, L. (2016). A fifty-year sustainability assessment of Italian agro-forest districts. Sustainability, 8:32.

Redman, C. L. (2014). Should sustainability and resilience be combined or remain distinct pursuits? Ecology and Society, 19:37.

Refsgaard, J. C. and Henriksen, H. J. (2004). Modelling guidelines - terminology and guiding principles. Advances in Water Resources, 27:71-82.

Rist, L., Felton, A., Nyström, M., Troell, M., Sponseller, R. A., Bengtsson, J., Österblom, H., Lindborg, R., Tidáker, P., Angeler, D. G., Milestad, R., and Moen, J. (2014). Applying resilience thinking to production ecosystems. Ecosphere, 5:1-11.

Salt, D., Polhill, J. G., and Craig, T. (2016). GLAMURS deliverable 2.2: Report on the ontology generation and data and knowledge integration. Technical report. http://glamurs.eu/ wp-content/uploads/2017/01/WP2_Deliverable_2.2.pdf, accessed 2018-05-20.

Sarvajayakesavalu, S. (2015). Addressing challenges of developing countries in implementing five priorities for sustainable development goals. Ecosystem Health and Sustainability, 1(7):24.

Scheffer, M., Bascompte, J., Brock, W. A., Brovkin, V., Carpenter, S. R., Dakos, V., Held, H., van Nes, E. H., Rietkerk, M., and Sugihara, G. (2009). Early-warning signals for critical transitions. Nature, 461:53-59.

Scheffer, M., Carpenter, S., Foley, J. A., Folke, C., and Walker, B. (2001). Catastrophic shifts in ecosystems. Nature, 413:591-596. 
Scheffer, M., Carpenter, S. R., Lenton, T. M., Bascompte, J., Brock, W., Dakos, V., van de Koppel, J., van de Leemput, I. A., Levin, S. A., van Nes, E., Pascual, M., and Vandermeer, J. (2012). Anticipating critical transitions. Science, 338:344-348.

Schieritz, N. and Größler, A. (2003). Emergent structures in supply chains a study integrating agent-based and system dynamics modelling. In Proceedings of the 36th Annual Hawaii International Conference on System Sciences. https://www.researchgate.net/publication/221178642_Emergent_Structures_in_ Supply_Chains_-_A_Study_Integrating_Agent-Based_and_System_Dynamics_Modeling, accessed 2018-05-31, doi:10.1109/HICSS.2003.1174226.

Schlüter, M., Baeza, A., Dressler, G., Frank, K., Groeneveld, J., Jager, W., Janssen, M. A., McAllister, R., Müller, B., Orach, K., Schwarz, N., and Wijermans, N. (2017). A framework for mapping and comparing behavioural theories in models of social-ecological systems. Ecological Economics, 131:21-35.

Schlüter, M., McAllister, R. R. J., Arlinghaus, R., Bunnefeld, N., Eisenack, K., Hölker, F., Milner-Gulland, E. J., Müller, B., Nicholson, E., Quaas, M., and Stöven, M. (2012). New horizons for managing the environment: A review of coupled social-ecological systems modeling. Natural Resource Modeling, 25:219-272.

Schmolke, A., Thorbek, P., DeAngelis, D. L., and Grimm, V. (2010). Ecological models supporting environmental decision making: a strategy for the future. Trends in Ecology and Evolution, 25:479-486.

Schulze, J., Müller, B., Groeneveld, J., and Grimm, V. (2017). Agent-based modelling of socialecological systems: Achievements, challenges, and a way forward. Journal of Artificial Societies and Social Simulation, 20(2):8. http://jasss.soc.surrey.ac.uk/20/2/8.html, accessed 2018-05-31.

Seidl, R. (2015). A functional-dynamic reflection on participatory processes in modeling projects. Ambio, 44(8):750-765.

Shearer, R., Motik, B., and Horrocks, I. (2008). HermiT: A highly-efficient OWL reasoner. OWLED 2008. OWL: Experiences and Directions. Fifth International Workshop, Karlsruhe, Germany, October 26-27, 2008.

Siddig, A. A. H., Ellison, A. M., Ochs, A., Villar-Leeman, C., and Lau, M. K. (2015). How do ecologists select and use indicator species to monitor ecological change? Insights from 14 years of publication in Ecological Indicators. Ecological Indicators, 60:223-230.

Silver, N. (2012). The Signal and the Noise: The Art and Science of Prediction. Penguin UK.

Silver, N. (2016). Who will win the presidency. https://projects.fivethirtyeight.com/ 2016-election-forecast/ accessed 2018-05-30.

Sirin, E., Parsia, B., Cuenca Grau, B., Kalyanpur, A., and Katz, Y. (2007). Pellet: A practical OWL-DL reasoner. Web Semantics: Science, Services and Agents on the World Wide Web, $5: 51-53$.

Smith, P. B., Bond, M. H., and Kagitcibasi, C. (2006). Understanding Social Psychology Across Cultures. Sage Publishing. 
Steffen, W., Persson, A., Deutsch, L., Zalasiewicz, J., Williams, M., Richardson, K., Crumley, C., Crutzen, P., Folke, C., Gordon, L., Molina, M., Ramanathan, V., Rockstroöm, J., Scheffer, M., Schellnhuber, H. J., and Svedin, U. (2011). The Anthropocene: From global change to planetary stewardship. Ambio, 40:739-761.

STOWA/RIZA (1999). Smooth modelling in water management, good modelling practice handbook. Technical report, Dutch Department of Public Works, Institute for Inland Water Management and Waste Water Treatment.

Swinerd, C. and McNaught, K. R. (2012). Design classes for hybrid simulations involving agentbased and system dynamics models. Simulation Modelling Practice and Theory, 25:118-133.

ten Broeke, G. A., van Voorn, G. A. K., Ligtenberg, A., and Molenaar, J. (2017). Resilience through adaptation. PLoS ONE, 12(2):e0171833.

ten Broeke, G. A., van Voorn, G. A. K., Ligtenberg, A., and Molenaar, J. (2018). Cooperation can improve the resilience of common-pool resource systems against over-harvesting. This issue.

Tsarkov, D. and Horrocks, I. (2006). Fact++ description logic reasoner: system description. In Furbach, U. and Shankar, N., editors, Automated Reasoning. Third International Joint Conference, IJCAR 2006, Seattle, WA, USA, August 17-20, 2006. Proceedings., Lecture Notes in Computer Science 4130, pages 292-297. Springer, Berlin, Heidelberg.

van Apeldoorn, D. F., Sonneveld, M. P. W., and Kok, K. (2011). Landscape asymmetry of soil organic matter as a source of agro-ecosystem resilience. Agriculture Ecosystems and Environment, 140:401-410.

van der Sluijs, J. P., Craye, M., Funtowicz, S., Kloprogge, P., Ravetz, J., and Risbey, J. (2005). Combining quantitative and qualitative measures of uncertainty in model-based environmental assessment: the NUSAP system. Risk Analysis, 25:481-492.

van Lange, P. A. M., Joireman, J., Parks, C. D., and van Dijk, E. (2013). The psychology of social dilemmas: A review. Organizational Behavior and Human Decision Processes, 120:125-141.

van Voorn, G. A. K., Verburg, R. W., Kunseler, E.-M., Vader, J., and Janssen, P. H. M. (2016). A checklist for model credibility, salience, and legitimacy to improve information transfer in environmental policy assessments. Environmental Modelling \&3 Software, 83:224-236.

Vidal-Abarca, M. R., Suárez-Alonso, M. L., Santos-Martín, F., Martín-López, B., Benayas, J., and Montes, C. (2014). Understanding complex links between fluvial ecosystems and social indicators in Spain: An ecosystem services approach. Ecological Complexity, 20:1-10.

Voinov, A., Kolagani, N., McCall, M. K., Glynn, P. D., Kragt, M. E., Ostermann, F. O., Pierce, S. A., and Ramu, P. (2016). Modelling with stakeholders - next generation. Environmental Modelling \& Software, 77:196-220.

Walker, B. H., Carpenter, S. R., Rockstrom, J., Crépin, A.-S., and Peterson, G. D. (2012). Drivers, "slow" variables, "fast" variables, shocks, and resilience. Ecology and Society, 17:30.

Wilensky, U. (1999). NetLogo. Center for Connected Learning and Computer-Based Modeling, Northwestern University. Evanston, IL. https://ccl.northwestern.edu/netlogo/, accessed 2018-05-31. 
Yang, J., Chen, F., Xi, J., Xie, P., and Li, C. (2014). A multitarget land use change simulation model based on cellular automata and its application. Abstract and Applied Analysis, 2014. Article ID 375389, http://dx.doi.org/10.1155/2014/375389, accessed 2018-05-31.

Zellner, M., Watkins, C., Massey, D., Westphal, L., Brooks, J., and Ross, K. (2014). Advancing collective decision-making theory with integrated agent-based modeling and ethnographic data analysis: An example in ecological restoration. Journal of Artificial Societies and Social Simulation, 17(4):11. http://jasss . soc. surrey.ac .uk/17/4/11.html, accessed 2018-05-27.

Zurlini, G., Riitters, K., Zaccarelli, N., Petrosillo, I., Jones, K. B., and Rossi, L. (2006). Disturbance patterns in a socio-ecological system at multiple scales. Ecological Complexity, 3:119-128.

\section{Appendix 1}

To illustrate the potential advantages of the multi-ontology approach in ABM projects, we take as an example the "FEARLUS-SPOMM" model (Polhill et al., 2013), which was designed and implemented as part of the long-running FEARLUS (Framework for Evaluation and Assessment of Regional Land Use Scenarios) project, first described in Polhill et al. (2001). Several versions of the FEARLUS model were developed, the latest being FEARLUS-SPOMM, which coupled a species metacommunity model, SPOMM (Stochastic Patch Occupancy Metacommunity Model), which is an enhanced version of SPOMSIM (Moilanen, 2004), to the FEARLUS core. The purpose of FEARLUS-SPOMM was to examine the consequences of different possible government incentive schemes aimed at preserving and increasing biodiversity on farmers' lands. By the time FEARLUS-SPOMM was implemented, a prototype feature had been added to FEARLUS (Polhill et al., 2008) to produce what is called here a model ontology, and a partial project ontology, and Polhill et al. (2013) includes a model ontology encoded as a UML diagram, but FEARLUSSPOMM was designed and implemented without use of a separate system ontology. We aim to show here that, even devised in retrospect, such an ontology can significantly improve ABM transparency.

Figure 4 shows an adapted version of the FEARLUS-SPOMM model ontology, at lower left, along with versions of a FEARLUS project ontology (top), and a FEARLUS-SPOMM system ontology (lower right). The FEARLUS project ontology is a (partial) representation of the modellers' conceptual model of the FEARLUS project domain - regional land use scenarios prior to the work leading up to the coupling of FEARLUS and SPOMM. The FEARLUS-SPOMM model ontology is a (partial) representation of the addition to this conceptual model needed to include the species metacommunity model, and the types of government incentive schemes to be explored.

Links between the three ontologies are shown by the thicker, dotted lines. There are four types of relation between concepts in the ontologies. Three of these occur both within the three labelled ontologies, and linking nodes in different ontologies: "subclass-of", "part-of", and "relates-to". The node at the tail of a "subclass-of" link names a subclass, or subconcept, of the concept named by the node at the head of the link. Instances of the concept named at the tail of a "part-of" link are, or can be, parts of instances of the concept named at its head. The "relates-to" link stands for any other type of relationship between instances of the concepts named at its head and tail; these links are labelled to identify the relationship (in the full version of the ontology, these relationships would themselves be formally defined). The fourth type of link, "represents", runs between a node in the model ontology, and a node in either the system or project ontology, specifying that an instance of the model ontology concept at the link tail 


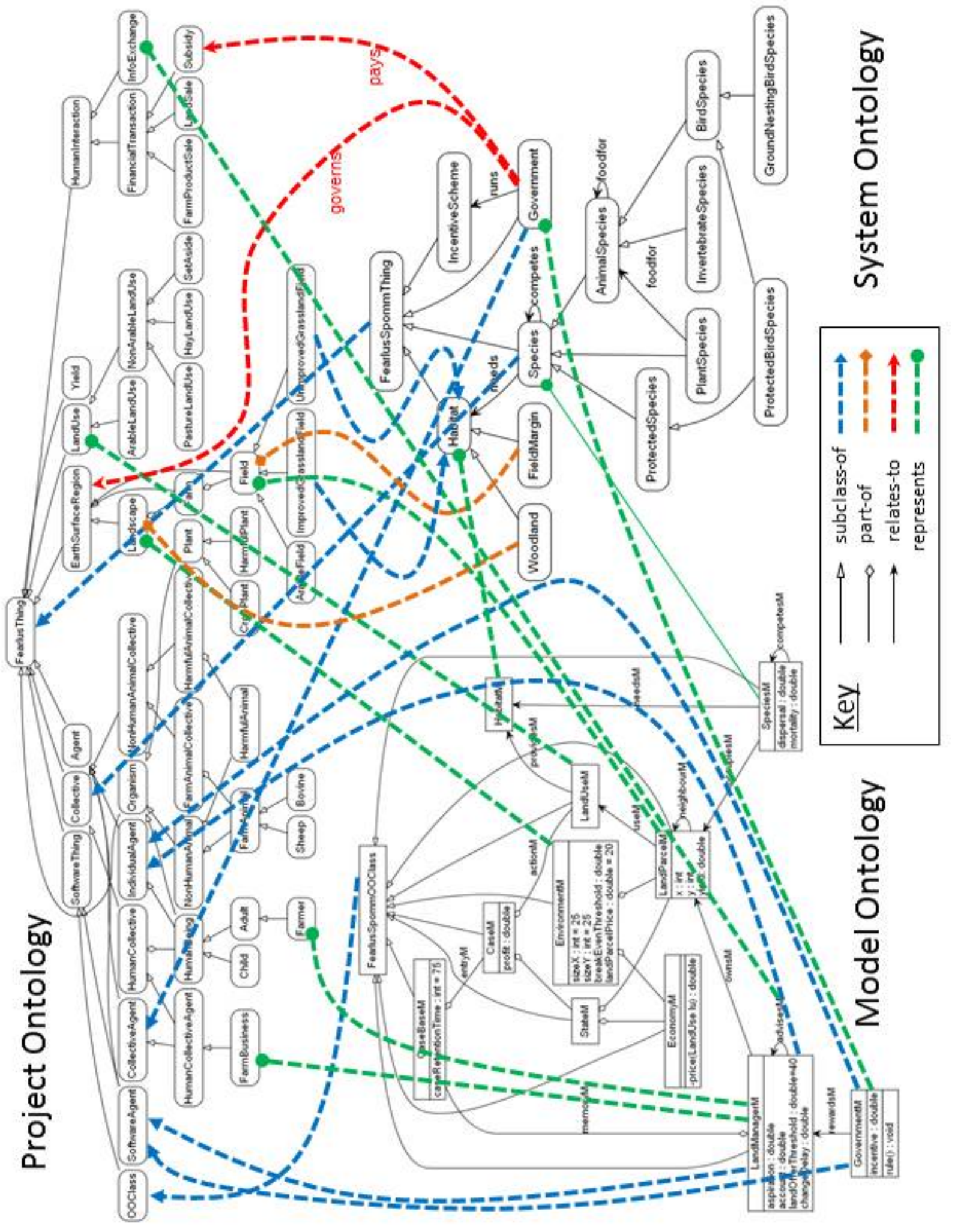


is intended to represent an instance of the system or project ontology concept at the link head. We draw attention to the following points in the figure:

- All three ontologies shown contain fewer nodes, links, and types of links than full ontologies would require. The representation ontology is not shown separately; it is visualized as the set of "represents" links. Within the project ontology, only "subclass-of" and "part-of" links are shown. A few "relates-to" links are shown in the model ontology and system ontology.

- Names of nodes within the model ontology are given a final "M" as a reminder that they are pieces of software. All the nodes in this ontology stand for "classes" in the object-oriented language Objective C, in which FEARLUS-SPOMM is written. Just two of these nodes identify classes of SoftwareAgent: pieces of software that encode procedures for making decisions and assessing the results of those decisions as a program runs. (The distinction between "software agents" and other pieces of code depends on how they are viewed by the modeller as much as on their intrinsic properties.)

- The two classes of SoftwareAgent within the model ontology (LandManagerM and GovernmentM) also have "subclass-of" links to the node IndividualAgent in the project ontology. An "individual agent" contrasts with a "collective agent": the decisions of the latter, but not the former, emerge out of the interactions of other agents that they (in some sense) comprise. Thus in reality, the decisions of a government - even in a dictatorship - arise as a result of interactions between multiple individuals, and indeed, smaller collective agents such as committees and departments - but the FEARLUS-SPOMM GovernmentM agent has no such internal structure. The situation with regard to the other class of IndividualAgent within FEARLUS-SPOMM, the LandManagerM, is more complicated: it is unclear whether a LandManagerM represents a human individual (a farmer), or a farm business, which generally includes more than one person, and has a distinct legal existence (in the normal FEARLUS context of the UK). In the formal representation ontology, these links would be annotated with classificatory terms, themselves part of a hierarchy of types of representation, designed to elucidate both those features of the link head which the link tail captures, and those it does not.

- Turning to parts of the physical world, a LandParcelM represents a Field (in the project ontology: fields are common to all systems modelled in the FEARLUS project). But features attached to LandParcelM show that its spatial position can be specified by a single pair of integer coordinates, indicating that the LandParcelMs form a grid, and are all of the same size. Real fields do not in general conform to this pattern, and have many other conceptually important features which FEARLUS's LandParcelMs lack. Of course, even the project ontology cannot include all the features even of something as relatively simple as fields, but features and relationships can be added to those ontologies as they become significant in ongoing work, for example through being mentioned in a stakeholder or expert interview. They would then serve as a reminder of what a model leaves out, and a source of suggestions for enhancing it.

- The EnvironmentM is shown as representing a project ontology Landscape, but in this case, the model ontology concept actually contains elements that do not correspond to anything in a real-world landscape, but to the prices of farm products. The project ontology as shown omits these; if constructed in advance, it would certainly have included them, but this illustrates another general point: a simulation model itself can suggest lacunae in the conceptual model encoded in a project or system ontology. Conversely, the fact that 
EnvironmentM has no straightforward counterpart in the project or system ontology at least casts some doubt on the way the simulation model is structured.

- Other nodes in the model have no "represents" links at all. All except the top-level FearlusSpommThing node, which is a notational convenience, relate to the way in which a LandManagerM decides what LandUseM to apply to a LandParcelM. This feature of the model (encoded in the FEARLUS-SPOMM classes StateM, CaseM and CaseBaseM) is intended to implement a simplied version of "Case-Based Reasoning" (Aamodt and Plaza, 1994), an artificial intelligence technique in turn claimed to capture features of human expert decision-making; but how far the FEARLUS-SPOMM model is intended to represent how real farmers (or farm businesses - see above) choose land uses is not clear. CaseBaseM could be taken to represent either the personal memory of a Farmer, or the "institutional memory" of a FarmBusiness. It is worth noting that earlier versions of FEARLUS employed different decision-making methods, see for example Polhill et al. (2001).

- The links between the system and project ontologies also point up interesting issues, in this case with regard to the integration of two conceptual models. The Government node in the system ontology has three links to nodes in the project ontology. One is a "subclass-of" link to the CollectiveAgent node, the others are "relates-to" links noting that a Government governs an EarthSurfaceRegion (the project ontology does not include more specific nodes for polities, this might suggest adding at least one such node, but the model ontology does not appear to need to include this concept), and that a Government pays Subsidy (again, this might suggest the need for additional nodes and in this case, more information about how the model represents this fact seems desirable).

- The other system-project links concern the system concepts Species and Habitat. Species is linked to the project node Collective as a subclass, but this raises the question of what "species" means in the context of a species metacommunity model. The individual members of a species are not in fact represented, only the presence or absence of some members of the species in specific areas, and their ability to persist there, and spread to neighbouring areas, so the species is treated more like an amorphous mass than a collective - which is, in the context of this type of conceptual model, quite valid. But this suggests that the concept does not fit easily into the conceptual model underlying FEARLUS, so modellers should beware of problems arising from this imperfect fit. Similarly, "subclass-of" links going the other way, from the project to the system ontology, link UnimprovedGrasslandField and ImprovedGrasslandField to Habitat. That seems unexceptionable - unimproved and improved grassland fields are both surely types of habitat. But should there also be a subclass-of link from Field to Habitat? Or perhaps habitats should not be encoded in nodes at all, but in links: a given type of field being a "habitat-for" a particular range of species.

The foregoing examples demonstrate how the use of ontologies can bring to the surface deep issues that arise in modelling, concerning the relationships between conceptual and software models, and between conceptual models themselves. Such issues arise particularly when comparing models (Cioffi-Revilla and Gotts, 2003), when extending the domain of a modelling project (as in the case of FEARLUS-SPOMM), and when combining existing software or conceptual models (again, as in the FEARLUS-SPOMM case). Of course, we do not claim such tasks are impossible without the use of ontologies, but that, particularly with a modelling approach as expressive as ABM, they have great potential to assist in model development, assessment, comparison, extension and combination. 